\title{
An extended method for work and heat integration considering practical operating
} constraints

Leandro V. Pavão ${ }^{a 1}$, José A. Caballero ${ }^{b}$, Mauro A. S. S. Ravagnani ${ }^{a}$, Caliane B. B. Costa ${ }^{a}$ ${ }^{a}$ Department of Chemical Engineering, State University of Maringá, Av. Colombo, 5790, Bloco D90, CEP 87020900, Maringá, PR, Brazil

${ }^{b}$ Institute of Chemical Process Engineering, University of Alicante, Ap. Correos 99, 03080 Alicante, Spain

\section{Abstract}

The development of methodologies for the simultaneous work and heat integration has increasingly been the focus of recent research. Approaches may vary among optimization and heuristic-based methods considering direct and indirect work exchange, in addition to, or with the development of new strategies for heat recovery. This work presents a strategy for the synthesis of work and heat exchanger networks (WHEN) considering the use of single-shaft-turbinecompressor (SSTC) units. The method is based on a meta-heuristic approach and aims fundamentally at synthesizing WHEN that may operate within industrial-like conditions, which are often narrower than those considered in the literature due to simplification assumptions. Therefore, in the present work, practical temperature upper/lower-bound constraints are considered for pressure manipulation units, and the number of coupled units per shaft is limited. Evidently, these constraints yield additional difficulties for the optimization method. Therefore, new calculation blocks are included in a previous block-based model. The method considers inlet and outlet temperatures as decision variables, making the maintenance of solutions within feasible range more efficient during the optimization runs. Moreover, a new Simulated Annealing (SA) based strategy is developed for deciding optimal compressor/turbine couplings in a model that considers a preset number of "slots" per shaft. The method aims at minimizing total annual costs (TAC) and is tested over four case studies. The first two are used both as benchmark for TAC comparison to those reported in the literature as well as for testing the new constraints. The other two cases are investigated for TAC and energy-wise improvements to original designs. Considerable economic improvements and better use of energy are attained in all cases. The method also proved efficient in maintaining solutions within practical operating ranges.

Keywords: Optimization; Work and Heat Integration; Work and Heat Exchange Networks; Metaheuristics; Process Synthesis

\footnotetext{
${ }^{1}$ Corresponding author. Tel: +55 (44) 3011-4774, Fax: +55 (44) 3011-4793

E-mail address: leandropavao@gmail.com
} 


\section{Introduction}

Energy recovery is a matter of utmost importance in the general industry. Several processes demand energy in different forms. Heat is required for raising material stream temperatures and maybe typically provided by means of a heat carrier such as steam or hot oil. Some streams might require cooling, which may be performed by streams that act as "cold carriers”, usually operating in cycles that demand electricity for cooling or refrigeration. Common cooling stream examples are those produced in cold water towers and chillers. Electricity is also demanded when pressure raises are required in material streams by means of compression units. Electricity may as well be produced via turbines coupled to electric generators given a material stream that requires pressure lowering, contributing to energy recovery in plants. Aiming to recover as much energy as possible, industry has employed and constantly improved devices such as heat exchangers. Heat exchange devices such as the shell-and-tube heat exchanger have been applied since the beginning of the last century [1]. The optimal placement of heat exchangers given a set of hot and cold streams has become somewhat of an art, given the complexity of solving the heat exchanger network (HEN) problem to global optimality when considering reduction of external energy consumption and capital costs. Several prominent methods for seeking energy-efficient solutions at acceptable investments have been presented by scholars throughout the last half-century. A classic example is the Pinch Analysis [2], which laid groundwork for energy recovery targeting and has been widely applied in industry. Another important, more recent trend in heat integration has aimed at automaticity in the synthesis problem by means of approaches based on mathematical programming. An outstanding example on the subject is the stage-wise superstructure (SWS) model [3], whose concepts still serve as basis to several state-of-the-art HEN synthesis models. The interested reader is referred to a comprehensive review of the general HEN synthesis subject, including descriptions and contrasts between Pinch Analysis and mathematical programming approaches, by Klemeš and Kravanja [4]. An even more extensive review on Pinch Analysis and its main future directions has been recently published by Klemeš et al. [5].

The use of heat exchangers is well-established in the industry for heat exchange. Work exchange discussions, on the other hand, are considerably scarcer and have recently been the focus of academic attention. Studies on the matter may be split into two major approaches: direct and indirect work recovery [6].

The first concept for a "direct work exchanger", as an analogy to a heat exchanger, has been presented by Cheng et al. [7], and was called "flow work exchanger”. In brief, the device consisted of using displacement vessels with floating solid partitions, wherein a high-pressure (HP) fluid can compress a low-pressure (LP) one. The work exchange task proposed was sequential, but proper operation of the multiple valves in the system could lead to a nearly continuous process. A flow work exchanger is a basic approach for direct work recovery. The idea was proposed in 
1967, along with other direct work exchange devices through the following decades. Other direct work exchanger technologies are reviewed in detail by Andrews and Laker [8], with focus on the desalination industry. It was only in 1996 that the first discussions on the synthesis work exchange networks (WEN) - the optimal placement of work exchange units given a set of high and lowpressure streams - arose [9]. Auxiliary pressure/work diagrams as an analogy to the temperature/enthalpy diagrams from Pinch Analysis were applied. More recent WEN synthesis contributions employing direct work exchange include, for instance, the graphical method of Zhuang et al. [10], which explored isothermal, isentropic and polytropic conditions for those devices, and the thermodynamic modeling of Amini-Rankouhi and Huang [11], which was able to provide a prediction of maximum amount of recoverable mechanical energy prior to the WEN design.

It is considered that an indirect work exchange task is performed when pressure energy is converted into another intermediate form of energy (e.g., mechanical or electrical) and then converted back to pressure energy. This sort of power recovery is widely seen in the industry, especially with the intermediate energy form being electricity. Plants using turbine/generator devices producing electricity for internal consumption, for instance, in compressors, are common. The produced electricity may as well be used in other electrical processes in the plant or sold to the grid. Under this scope, several studies that aim at minimizing shaft-work required by compressors and at maximizing shaft-work produced by expanders have been carried out. Some examples are worth highlighting here. The work of Aspelund et al. [12] presents a method based on Pinch Analysis (Extended Pinch Analysis and Design, ExPAnD) with some fundamental heuristics for determining optimal pressure manipulation routes and sizing in order to minimize energy requirements in sub-ambient processes. Those ideas served as basis for the work of Wechsung et al. [13], who extended the methodology by employing mathematical programming techniques and exergy analysis aiming at process irreversibility reduction, also considering the heat integration targeting of the process via Pinch Analysis concepts. In Wechsung et al.'s approach, a stream could pass through a heat recovery region between pressure manipulations. Fu and Gundersen [14] proposed a series of theorems for the correct placement of compressors and expanders also considering the possible heat integration of the process aiming at minimizing exergy consumption. Onishi et al. [15] considered unclassified process streams in their optimization-based approach, which aimed at minimizing a total annual costs function (comprising capital and operating costs) rather than performing an exergy-based analysis. Indirect work exchange performed via single-shaft-turbine-compressor (SSTC) coupling (also called indirect work exchanger) is the elementary idea of having an expansion process occurring in a (set of) turbine(s) to rotate a single-shaft which is coupled to a (set of) compressor(s). In this case, the pressure energy of the stream being expanded in the turbine intermediately becomes mechanical energy. Besides SSTC, the literature often refers to this sort of apparatus as 
turboexpander-compressor (TEC), expander-compressor (EC), or in some cases simply turboexpander. One of the most notable applications of turbine-compressor coupling is in power recovery trains (PRT) of fluid catalytic cracking (FCC) plants. Back in the 1940s, in early FCC plants, flue gas streams were released directly to the atmosphere. The first reports of plants using such stream for power recovery date back to the 1960s [16]. The scheme consists of coupling the following unit operations: the flue gas expander, an air compressor, a steam turbine, and a motor/generator. If the expander produces more power than that required by the air blower, it is sent to the plant electrical system. In case there is lack of power, it is provided by the motor [17]. Another typical use of turbine-compressor couplings is in the natural gas liquid (NGL) recovery process [18]. First reports of the so-called turboexpander natural gas liquid recovery process date back to the 1960s [19], wherein work exchange between high-pressure top gas from a cold separator and low-pressure top gas from a demethanizer unit was performed. Other applications include air separation processes [20], cooling cycles [21] and the ethylene production process [22].

The employment of such an apparatus is well established in the industry. However, discussions on methods for their optimal placement given a set of high and low-pressure streams, i.e., the synthesis of work exchange networks using SSTC units, are relatively recent. A method for WEN synthesis via turbine-compressors coupling was firstly presented by Razib et al. [23]. It was an approach based on a mathematical programming model derived from a multi-stage superstructure. In each stage, a heater/cooler was present along with a possible stream split. Each split branch comprised a pressure manipulation unit. In low-pressure streams, those could be utility compressors and compressors that were part of a SSTC coupling. Each high-pressure stream split branch comprised either a valve, a utility turbine or turbines that were part of the SSTC coupling. Later, Du et al. [24] presented an approach based on the transshipment model for synthesizing WEN with indirect work transfer.

In a set of material streams, not only work, but heat integration opportunities may arise as well. Regarding the opportunity of simultaneously integrating both forms of energy, several authors have proposed methods for the optimal placement of both work and heat exchange devices given a set of streams. This gave rise to the work and heat exchange network (WHEN) concept, which could merge mature HEN synthesis ideas to the nascent WEN synthesis trends. Onishi et al. [25] used a similar idea to that of Wechsung et al. [13], where streams pass through a heat recovery region and a pressure manipulation region. However, their method had as objective to reduce total annual costs instead of lowering process irreversibility. They replaced the Pinch Operator in the HEN section of their superstructure by the SWS [3], which allowed their approach to automatically generate HENs with optimal pressure manipulation routes. In some case studies, they allowed the use of SSTC units, which led to low-cost WHENs. Onishi et al. [26] later extended their framework by including Razib et al.’s [23] stream split scheme in their work 
recovery section and allowing multiple shaft coupling. A WHEN retrofit framework was also presented by Onishi et al. [27]. Huang and Karimi [28] presented a multi-stage model for WHEN synthesis including the SWS in the heat recovery stages and a WEN section similar to Razib et al.'s approach [23]. Huang and Karimi's model, however, was more flexible due to the possible use of either heaters or coolers for temperature correction at any stream, regardless of their original identification as hot or cold. In a more recent contribution, Onishi et al. [29] studied the synthesis of WHEN from both economic and environmental perspectives, applying a bi-objective model. Nair et al. [30] developed a broad framework, which included phase-changing streams and streams not being considered with hot/cold/HP/LP identities. Pavão et al. [31] presented a framework using the idea of streams passing multiple times through a heat recovery region with pressure manipulation units between each pass $[13,25]$. A matrix-based representation was proposed for matching the work and the heat recovery stages. The latter employs an enhanced HEN superstructure model [32]. Moreover, the scheme utilized a meta-heuristic method for the solution. The approach was later extended to handle multiple electricity-related scenarios [33]. The reader is also referred to comprehensive state-of-the-art reviews on the HEN/WEN/WHEN matter carried out by Fu et al. [34] and Yu et al. [35]. These include key thermodynamic insights, fundamental concepts, challenges and opportunities on the field.

Many WHEN synthesis approaches developed so far are optimization-based methods. Given the complexity of these problems, several simplifications might be needed in order for them to identify optimal solutions. Typically, temperature bounds are not considered or are wider than observed in industrial practice. This is notable especially regarding the compression process, which may yield very high temperatures. Seider et al. [36] point out that specialized units can operate at temperatures of up to $600{ }^{\circ} \mathrm{F}$ ( $\left.~ 518 \mathrm{~K}\right)$. However, they point out that more commonly observed operating upper bounds for compressors temperature range from $375{ }^{\circ} \mathrm{F}$ ( $463 \mathrm{~K}$ ) to $400{ }^{\circ} \mathrm{F}(\sim 477 \mathrm{~K})$, as recommended by manufacturers. These values are lower than those typically seen in literature WHEN solutions. In industry, multiple stage compression (with temperatures within the aforementioned ranges) with intercooling is a common apparatus, especially, in above ambient processes. Turbine operating temperatures may as well be limited. Also according to Seider et al. [36], in turbines, inlet temperatures of up to $1000{ }^{\circ} \mathrm{F}$ ( 811 K) can be handled. Another aspect that may render some operating constraints is the number of compressors/turbines coupled via a single-shaft. Literature solutions do not limit this value, and configurations with several units coupled to a single shaft are commonly presented. The implementation of such large couplings may present some issues regarding rotation speed maintenance and stream transportation issues, due to the fact that a large number of streams need to be transported towards the apparatus. Available space on the plant might be a problem as well, depending on the arrangement of the shaft [26]. Onishi et al. [26] tackled this problem by considering multiple 
shafts, but did not limit the number of units per shaft, which led to solutions with up to twelve coupled units.

Aiming at more realistic solutions, the method developed in the present work attempts to consider the aforementioned constraints more rigorously. The main methodology innovations regard: (i) novel programming routines were implemented into unit blocks for attaining these practical configurations taking as a basis the master structure of our previous framework [32]. The main change is that these blocks use temperatures rather than shaft-work as decision variables, which makes the solution method considerably more efficient in finding solutions with units operating within narrower, industrial-like temperature ranges. (ii) Considering several shafts with "slots" for coupling compressors and turbines. In our previous approach, these couplings were preset and occurred in a single shaft. In this work, a new meta-heuristic step based on Simulated Annealing was included for finding the optimal coupling configuration. Another important aspect of this work is the proposal of an ammonia plant case study based on a sample model of Aspen Plus [37]. Streams with heat/work integration potential were identified and their property data from PengRobinson equation of state was extracted and fit for use as a WHEN synthesis example.

Evidently, with the new calculation blocks, the number of variables increases in comparison to our previous framework, which leads to a more complex problem. In order to compare the efficiency of our algorithm to other literature WHEN synthesis approaches, two conceptual examples are taken for optimal costs benchmarking, neglecting and considering the proposed constraints. Two industrial design cases are used as well, which include an air separation process via Ion Transport Membrane (ITM) and the newly proposed ammonia plant case.

\subsection{Problem statement}

A set of process streams is given. According to their supply and target conditions, they may receive pressure-wise classifications as high or low pressure (HP/LP) and temperature-wise classifications as hot or cold. In general, electricity and external hot and cold utilities are available for use in compression, heating and cooling tasks. A set of compressors, turbines, valves, heat exchangers (matching two process streams), heaters and coolers must be allocated along the process streams in order for them to reach target pressure and temperature conditions. Compressors and turbines may be coupled via single-shaft. Multiple couplings may be performed. If in a coupling, there is a lack of shaft-work, a helper motor is used. Conversely, in case of shaftwork surplus, a generator is employed and electricity is considered as sold to the grid.

The following constraints are defined:

(i) Maximum compressors discharge temperature: $375^{\circ} \mathrm{F}(463.71 \mathrm{~K})$ [36]

(ii) Maximum turbines inlet temperature: $1000^{\circ} \mathrm{F}$ (810.93 K) [36]

(iii) Minimum compressors inlet and turbines outlet temperatures are defined according to process conditions; 
(iv) Maximum shaft-work value for each unit type may be defined;

(v) Maximum number of coupled units per shaft will vary between 2 and 4 (different values will be explored in each case study)

(vi) Streams must be mixed at equal pressures;

Streams undergoing pressure manipulations in compressors/turbines/valves are assumed as ideal gases, with known heat capacity and polytropic exponent (a specific case with non-constant heat capacity is approached in this work for a stream which does not require pressure manipulation, see example 4, Section 3.4). Isentropic efficiencies for compressors/valves and Joule-Thompson coefficients for valves are known. Pressure drop due to piping or heat exchange units is neglected. Functions for annualized capital and operating costs from equipment design parameters are given. With the aforementioned problem information, a work and heat exchange network must be synthesized with minimal total annual costs (TAC), which comprises both capital and operating costs.

\section{Work integration framework}

The model developed here aims to tackle the WHEN synthesis problem considering more practical constraints during the identification of designs. It takes as a basis the master structure concept presented in our previous work [31] and revamps it by including new structural possibilities.

Briefly, in the master structure, a hot or cold stream may be modeled to pass through the heat recovery section (HEN stage) several times and with different identities. The HEN stage of the master structure is modeled with the enhanced SWS [32], which is an extended version of the original SWS [3]. The enhanced SWS comprises an extra stream split branch for allocation of utilities, and the derived model does not include the non-isothermal mixing consideration. The SWS [3] is a classical mathematical programming approach in HEN synthesis, and the reader is referred to the aforementioned works [3,32] for in-depth explanations on model derivations. After each pass through the HEN stage there is the work recovery section (WEN stage), in which streams pressure may be manipulated or, if needed, the stream temperature may be corrected via heaters/coolers. Those tasks are programmed in our method as blocks containing calculation instructions for each unit type. With that approach, a master structure can be built placing different blocks in the "slots" of the WEN section.

Previously [31], these blocks included compressors, turbines, valves, heaters, and coolers. In this work, "hybrid" blocks are included in the formulation. For instance, one block may contain a compressor with a pre-cooler, and have associated two decision variables (for sizing each of these units). Those decision variables are temperature values, differing from our previous approach, which used shaft-work as main decision variables. That is advantageous since this work aims at considering practical temperature limitations of compressors and turbines (as stated in Section 
1.1). In this strategy, the meta-heuristic solution algorithm may directly correct a temperature value if it is out of boundaries prior to evaluating the objective function. In the previous approach, when manipulating shaft-work, temperatures were obtained from calculation and required some sort of penalization if they were out of boundaries. Moreover, the new blocks include the possibility of using parallel units. That is particularly useful if units have a maximum shaft-work limitation, so two or more units are employed in parallel. Hybrid blocks are presented in detail further in this section.

Furthermore, the present framework also includes the possibility of using multiple shafts for single-shaft-turbine-compressor (SSTC) couplings. That is advantageous due to space limitations or operating difficulties caused by the coupling of too many units. The number of coupled units may be constrained in the model.

Figure 1 (a)-(c) shows representations of the master structure. For instance, some passes of a stream that is originally cold and requires compression (Cold/Low-pressure) may be modeled with hot identities. At the end of those passes, compression tasks are performed. That type of modeling is due to the fact that the compression may be performed in multiple stages with intercooling for higher energetic efficiency. Conversely, given a high-pressure stream that requires cooling one might find it advantageous to increase temperature prior or between turbines for raising shaft-work generation. Those modeling situations are illustrated in the master structure depicted in Figure 1 (a), which is also presented according to a generic stream numbering system ( $w$ index). Figure 1 (b) depicts the HEN superstructure [32] that is used in this work, which requires numbering according to sets of hot $(i)$ and cold $(j)$ streams. Note that some information regarding $w$ equivalence as $i$ or $j$ is required for coupling the master structure to the HEN superstructure. Figure 1 (c) presents a master structure for another case, comprising one hot/LP stream and a cold/HP stream. Considering the multiple stage compression/expansion, those stream passes can be modeled without changing identities. The equivalence of streams $w$ index to $i$ or $j$ is intuitive in that case, in contrast to Figure 1 (a) and (b). Figure 1 (d) depicts the $M$ matrix that is used for performing such a conversion ( $w$ to $i, j$ indexes) process. It contains information regarding stream pass and original stream identities, in addition to the unit that is placed in the WEN section. The binary IsLinked(w) vector states whether a stream $w$ is a continuation of the previous stream $w-1$ or is a new stream. The binary Aux(w) vector contains data regarding whether a pressure manipulating unit is classified as “auxiliary” in the WEN stage. Auxiliary pressure-changing units are those that mandatorily reach the target pressure for a stream, while, in common pressure manipulating units, discharge pressures may vary. Note that final heaters/coolers are inherently auxiliary units (i.e., reach target temperatures) regardless of the $\operatorname{Aux}(w)$ variable, and may only be placed at the end of the last pass of a given stream. The new $\operatorname{Par}(w)$ vector contains information regarding the number of parallel units in a given pressure manipulation block (see units 4 and 5 in Figure 1e). As previously stated, multiple shafts are 
present in the model. The data contained in $\operatorname{SSTC}(w, f)$ is related to what shaft a given unit is coupled (see also Figure 1g). Figure 1e presents all possible blocks that may be allocated in the slots of the WEN stages. The new blocks 4 and 5 are those which were previously described as "hybrid" in this section. Note that blocks $4 / 5$ and $4 * / 5 *$ differ in that the latter has parallel units $(\operatorname{Par}(w)>1)$. For block 5, it should be noted that a valve is present as a parallel unit as well, and it is always placed in the last sub-stream. For instance, if $\operatorname{Par}(w)=3$, units in sub-streams $f=1$ and $f=2$ are turbines, and in $f=3$ it is a valve. New blocks 6 and 7 are correction coolers/heaters. These are required in some particular situations. For instance, if a given HP stream is at a temperature that is higher than maximum turbines operating temperature, a hot stream pass with a correction cooler in the WEN section may be included prior to the stream pass that has the heater/turbine block. That cooler has no decision variables associated, and it will always act to make the stream reach a preset target temperature (which can be the operating temperature upper bound for turbines). If such a temperature value, or an even lower one, is reached prior to the block via heat exchange, it is simply by-passed. Evidently, in case the temperature of the stream entering the heater/turbine block is exactly the upper-bound value, the pre-heater duty is null. If by means of heat exchange, such a temperature is lower than the target, some heat duty may be present in the pre-heater. In the compressor case, a stream may require some heating prior to that device, for instance, in order to safely avoid multiple phases occurring in it. Figure 1f presents a hot and a cold stream pass (regardless of the original stream identity). In building the master structure, we restrict cooling and compression units to be placed only after a hot pass, while heating and expansion units may be placed only after cold passes. Finally, Figure 1g illustrates the multiple shafts concept. If for a given shaft, there is a shaft-work lack, an auxiliary motor is used. In the surplus case, an auxiliary generator is applied. 


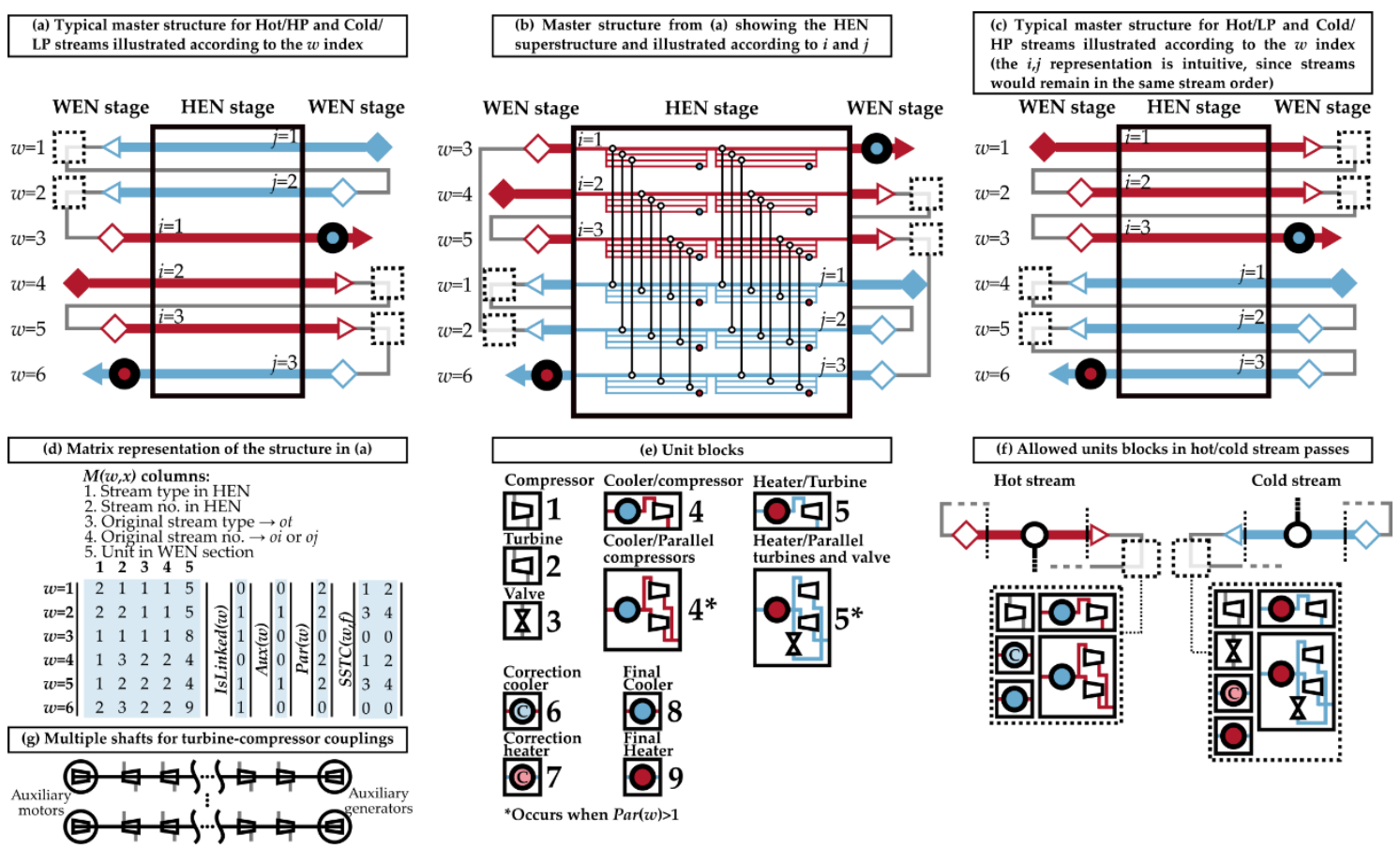

Figure 1. (a,b,c) Master structure representation; (d) matrix representation of a master structure; (e) unit blocks; (f) blocks that can be used in hot/cold streams; (g) representation of multiple shafts

\subsection{Implementation}

This subsection presents the mathematical expressions that are included as instructions in each of the new calculation block routines (blocks 4, 5, 6 and 7), as well as some comments on how they are implemented in the algorithm. Furthermore, comments are also included regarding the multiple shaft implementation.

Single compressor/turbine/valve blocks (1, 2 and 3), as well as final cooler/heater (8 and 9) blocks were already presented in the previously developed basis framework [31].

\section{Cooler/compressor (Block 4):}

In this block, firstly, the heat load for the cooler that comes prior to the compressor is calculated:

$$
\text { Qpre }_{w}=C P_{w}\left(\text { Tprein }_{w}-\text { Tpreout }_{w}\right), w \in N G
$$

where Tprein $_{w}$ retrieves the final temperature from the stream pass through the HEN stage. Considering that pass as a hot one, this means the temperature after the final stage mixer in the HEN superstructure. Tpreout ${ }_{w}$ is the outlet temperature from the cooler. It is worth noting that Tpreout $_{w}$ is set in this work as a decision variable which will be manipulated during the optimization algorithm execution. $C P_{w}$ is the heat capacity flowrate. The heat exchange area (which is later used for obtaining capital costs) calculation begins with the logarithmic mean temperature difference, as follows: 


$$
\text { LMTDpre }_{w}=\frac{\text { (Tprein } \left._{w}-\text { Tcuout }_{n}\right)-\left(\text { Tpreout }_{w}-\text { Tcuin }_{n}\right)}{\ln \left(\frac{\text { Tprein }_{w}-\text { Tcuout }_{n}}{\text { Tpreout }_{w}-\text { Tcuin }_{n}}\right)}
$$

$w \in N G, n \in N C U$

where Tcuin $_{n}$ and Tcuout $_{n}$ are inlet and outlet temperatures of the cold utility $n$.

In case that $\left(\right.$ Tprein $_{w}-$ Tcuout $\left._{n}\right)$ - $\left(\right.$ Tpreout $_{w}-$ Tcuin $\left._{n}\right)$ tends to zero, LMTDpre ${ }_{w}$ tends to the arithmetic mean temperature difference. However, direct substitution into the equation renders computational issues (division by zero). In that particular situation, the following equation is used for obtaining $L M T D p r e_{w}$ :

$$
\begin{aligned}
\text { LMTDpre }_{w}= & \text { Tprein }_{w}-\text { Tcuout }_{n} \\
& w \in N G, n \in N C U
\end{aligned}
$$

The global heat transfer coefficient for coolers is obtained from individual convective heat transfer coefficients for the hot stream $\left(h h_{\mathrm{i}}\right)$ and cold utility $\left(h c u_{n}\right)$ as follows:

$$
\begin{aligned}
\text { Ucu }_{i, n}= & \frac{1}{\frac{1}{h h_{i}}+\frac{1}{h c u_{n}}} \\
& i \in N H \mid i=M_{w, 2}, n \in N C U
\end{aligned}
$$

And, finally, the area $\left(\right.$ Apre $\left._{w}\right)$ is obtained with:

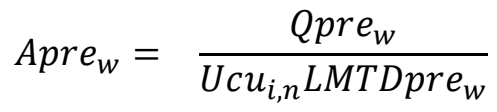

$$
\begin{aligned}
& w \in N G, i \in N H \mid i=M_{w, 2}, n \in N C U
\end{aligned}
$$

The following equations regard the compressor calculations in case that $\operatorname{Par}_{w}=1$. That is, the block does not have the possibility of compressors operating in parallel after stream split.

$$
\text { Work }_{w}=C P_{w}\left(\text { Tout }_{w}-\text { Tin }_{w}\right), w \in N G
$$

where Work $_{w}$ is the required shaft-work rate in the compressor and $\operatorname{Tin}_{w}$ retrieves its value from Tpreout $_{w}$. Tout $w_{w}$ is the compressor discharge temperature, and also the second decision variable associated to this block. The next step in the block instructions is the calculation of the discharge temperature considering a reversible process:

$$
\text { Trevout }_{w}=\eta_{c} \cdot\left(\text { Tout }_{w}-\text { Tin }_{w}\right)+\text { Tin }_{w}, w \in N G
$$

where $\eta_{c}$ is the isentropic process efficiency. The outlet pressure may then be calculated as follows:

$$
\text { pout }_{w}=\exp \left(\ln \left(\text { pin }_{w}\right)-\kappa \cdot \frac{\left(\ln \left(\operatorname{Tin}_{w}\right)-\ln \left(\text { Trevout }_{w}\right)\right)}{\kappa-1}\right), w \in N G
$$

where $\kappa$ is the polytropic exponent. In case this is an "auxiliary" block $(\operatorname{Aux}(w)=1)$, pout $_{w}$ is enforced to be equal to the target stream pressure, instead of calculated as in the regular block case. This yields a reduction in the degrees of freedom of this calculation block. Tout ${ }_{w}$ is maintained as the only decision variable, while Tpreout $_{w}$ becomes a calculated value. Note that in the auxiliary block situation these equations ((6)-(8)) are input in the program after some algebra so that Tpreout $_{w}$ is isolated and can be found in a straightforward calculation procedure. 
Next, after the calculations for a given compressor, the ComWork variable is used to compute the total shaft-work associated to compressors coupled to a given shaft $s$.

$$
\text { ComWork }_{s} \leftarrow \text { ComWork }_{s}+\text { Work }_{w} \text {, if SSTC } \text { Sw,f }_{\text {Som }} \in \text { NSh, } f \in N F
$$

Or, if the compressor is not coupled to turbines, TotalCompWork is used to compute the total shaft-work of standalone compressors:

$$
\text { TotalCompWork } \leftarrow \text { TotalCompWork }+ \text { Work }_{w} \text {, if SSTC } C_{w, f}=0, f \in N F
$$

In case $\operatorname{Par}_{w}>1$, the stream $w$ is split into $\operatorname{Par}_{w}$ branches after the pre-cooler. At each branch a compressor is present, whose calculations begin with the same work-related calculation performed by Eq. (6), and continues with Eq. (11). Note that $W_{o r k}$ in this case is the total shaftwork required considering the (Tout $t_{w}-\operatorname{Tin}_{w}$ ) temperature increase. That is equal to the sum of the shaft-work in all parallel compressors. For each compressor, the shaft-work is obtained as follows:

$$
\text { ParWork }_{w, f}=F w_{w, f} \cdot C P_{w}\left(\text { Tout }_{w}-\text { Tin }_{w}\right), w \in N G, f \in N F
$$

where $F w_{w, f}$ is the flowrate fraction that is deviated to a given stream split branch and also a decision variable. Note that discharge pressures must be equal in all compressors. Eqs. (7) and Eq. (8) are used for calculating pout ${ }_{w}$.

For the auxiliary parallel compressors case $(\operatorname{Par}(w)>1$ and $\operatorname{Aux}(w)=1)$, Tout $_{w}$ and $F w_{w}$ remain as decision variables, while Tpreout $t_{w}$ becomes a dependent one.

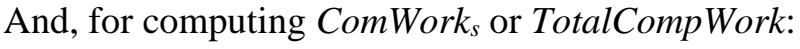

$$
\begin{gathered}
\text { ComWork }_{s} \leftarrow \text { ComWork }_{s}+\text { ParWork }_{w, f}, \text { if } \operatorname{SSTC}_{w, f}=s, s \in N S h, f \in N F \\
\text { TotalCompWork } \leftarrow \text { TotalCompWork }+ \text { ParWork }_{w, f}, \text { if SSTC } \text { S }_{w, f}=0, f \in N F
\end{gathered}
$$

\section{Heater/turbine (Block 5):}

Analogously to Block 4, a temperature manipulation device is placed prior to the pressure manipulation one. That is, a pre-heater is placed prior to a turbine. As in Block 4, the outlet temperature of this device is a decision variable, which is manipulated by the optimization approach. The heat load of the pre-heater is calculated as follows:

$$
\text { Qpre }_{w}=C P_{w}\left(\text { Tpreout }_{w}-\text { Tprein }_{w}\right), w \in N G
$$

Area calculations are performed in an analogous manner to Eqs. (2)-(5), with pre-heater hot end temperatures being Tpreout ${ }_{w}$ and Thuin $_{m}$ (hot utility $m$ inlet temperature) and the cold end ones being Tprein $_{w}$ and Thuout $_{m}$.

The shaft-work generated in the turbine is calculated as follows:

$$
\text { Work }_{w}=C P_{w}\left(\text { Tin }_{w}-\text { Tout }_{w}\right), w \in N G
$$

If $\operatorname{Par}(w)=1$, that is, a single turbine is placed after the pre-heater, calculations are as follows:

$$
\text { Trevout }_{w}=\operatorname{Tin}_{w}-\frac{\text { Tin }_{w}-\text { Tout }_{w}}{\eta_{t}}, w \in N G
$$


Then, outlet pressure for turbines is calculated with the same equation as in Eq. (8).

In this turbine, the decision variable is the discharge temperature. In case that this is an auxiliary block, it is treated analogously to the cooler/compressor situation: pout ${ }_{w}$ is fixed at the target value for the stream, Tout $_{w}$ remains a decision variable and Tpreout ${ }_{w}$ becomes a dependent one.

Analogously to Eq. (9), for total shaft-work generated by turbines coupled to the available $s$ shafts:

$$
\text { TurWork }_{s} \leftarrow \text { TurWork }_{s}+\text { Work }_{w}, \text { if SSTC } C_{w, f}=s, s \in N S h, f \in N F
$$

Or, for standalone turbines:

$$
\text { TotalTurbWork } \leftarrow \text { TotalTurbWork }+ \text { Work }_{w}, \text { if } \operatorname{SSTC}_{w, f}=0, f \in N F
$$

In case $\operatorname{Par}(w)>1, \operatorname{Par}(w)$ minus one turbine(s) and one valve are placed in parallel in Block 5. In the parallel compressors case, the outlet temperature is equal for all parallel units. In the parallel turbines/valve case, this is not true. Parallel turbines which have the same outlet pressure have the same discharge pressure. However, a valve placed in parallel to those units has a much smaller temperature reduction. Therefore, here, a decision variable called TurTout ${ }_{w}$ is used, which is the discharge temperature from the turbines. As in the cooler/compressors block, Tpreout ${ }_{w}$ is the other decision variable for this block. From these values, it is possible to obtain all the other important variables for this block, whose calculations are as follows (note that pout ${ }_{w}$ is calculated with Eq. (8)):

$$
\begin{gathered}
\text { ParWork }_{w, f}=F w_{w, f} \cdot \text { CP }_{w}\left(\text { Tin }_{w}-\text { TurTout }_{w}\right), w \in N G, f \in N F \\
\text { Trevout }_{w}=\operatorname{Tin}_{w}-\frac{\text { Tin }_{w}-\text { TurTout }_{w}}{\eta_{t}}, w \in N G \\
\text { TurWork }_{s} \leftarrow \text { TurWork }_{s}+\text { ParWork }_{w, f}, \text { if SSTC }_{w, f}=s, s \in N S h, f \in N F \\
{\text { TotalTurbWork } \leftarrow \text { TotalTurbWork }+ \text { ParWork }_{w, f}, \text { if SSTC }}_{w, f}=0, f \in N F \\
\text { ValTout }_{w}=\text { Tin }_{w}-\mu\left(\text { pin }_{w}-\text { pout }_{w}\right), w \in N G
\end{gathered}
$$

where ValTout ${ }_{w}$ is the outlet temperature from the valve and $\mu$ is the Joule-Thompson coefficient.

$$
\text { Tout }_{w}=\sum_{f<\text { Par }_{w}} F w_{w, f} \cdot \text { TurTout }_{w}+F w_{\text {Par }(w)} \cdot \text { ValTout }_{w}, w \in N G, f \in N F
$$

Note that in Eq. (24) the second $F w$ term has the Par(w) subscript, which represents the last parallel branch, which is the one where the valve is placed.

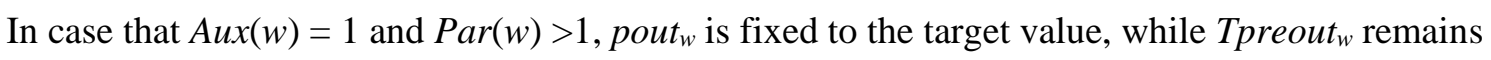
as a decision variable.

Correction cooler (Block 6): 
As already stated, this block was conceived for the particular case where correcting the temperature towards a preset lower value (Tcorout ${ }_{w}$ ) prior to entering a turbine is needed (note that Block 5 has a heater, which evidently cannot perform such a correction). That is, in case gas is hotter than the operating temperature upper bound of a turbine, an additional hot stream pass with Block 6 at its end can be created prior to the pass that has the expansion unit at its end. That initial hot pass allows the stream to be cooled down via heat exchange with other streams, and Block 6 guarantees that the temperature will be lowered to a given target. For instance, Seider et al. [36] provide $1000{ }^{\circ} \mathrm{F}(810.93 \mathrm{~K})$ as a common reference upper bound value for turbines operating temperature, but a given high-pressure, high-temperature gas stream may be supplied at a higher temperature. In such a situation, Block 6 can be placed with that reference temperature. If the optimization algorithm is able to find a solution where heat exchangers are placed upstream to the corrector so that the temperature of the stream is reduced below the upper bound, the corrector is simply bypassed. The heat load of this unit, in case it exists $\left(\right.$ Tcorin $_{w}>$ Tcorout $\left._{w}\right)$, is calculated as:

$$
Q \operatorname{cor}_{w}=C P_{w}\left(\text { Tcorin }_{w}-\text { Tcorout }_{w}\right), w \in N G
$$

The heat exchange area for this unit is calculated analogously to other areas previously presented. The hot end temperatures are Tcorin ${ }_{w}$ and Tcuout ${ }_{n}$ and the cold end ones are Tcorout ${ }_{w}$ and Tcuin $_{n}$.

\section{Correction heater (Block 7):}

The concept of a correction heater is analogous to the correction cooler. It might be needed, for instance, if increasing a stream temperature is desirable for safely avoiding multiple phases in the compressor. The heat load of this device is calculated as follows:

$$
\text { Corr }_{w}=C P_{w}\left(\text { Tcorout }_{w}-\text { Tcorin }_{w}\right), w \in N G
$$

Once again, heat exchange area calculations are analogous to previous area calculations in this work with hot end temperatures being Tcorout ${ }_{w}$ and Thuin $_{m}$ and the cold end ones being Tcorin $_{w}$ and Thuout .

Auxiliary motors/generators in couplings:

The following calculations are performed for each of the available shafts for later cost calculations of possible auxiliary motors or generators:

$$
\begin{aligned}
& \text { NetWork }_{s}=\text { ComWork }_{s}-\text { TurWork }_{S}, s \in N S h \\
& \text { SSTCWorkSurplus }_{s}=\text { NetWork }_{s}, \text { if NetWork } \text { N }_{S}>0 \\
& \text { SSTCWorkLack }_{s}=- \text { NetWork }_{s} \text {, if NetWork } k_{s} \leq 0
\end{aligned}
$$


Figure 2 presents the new blocks in detail, with the model decision variables placed at their representative points for compression/expansion blocks and illustrations of temperature correction blocks.
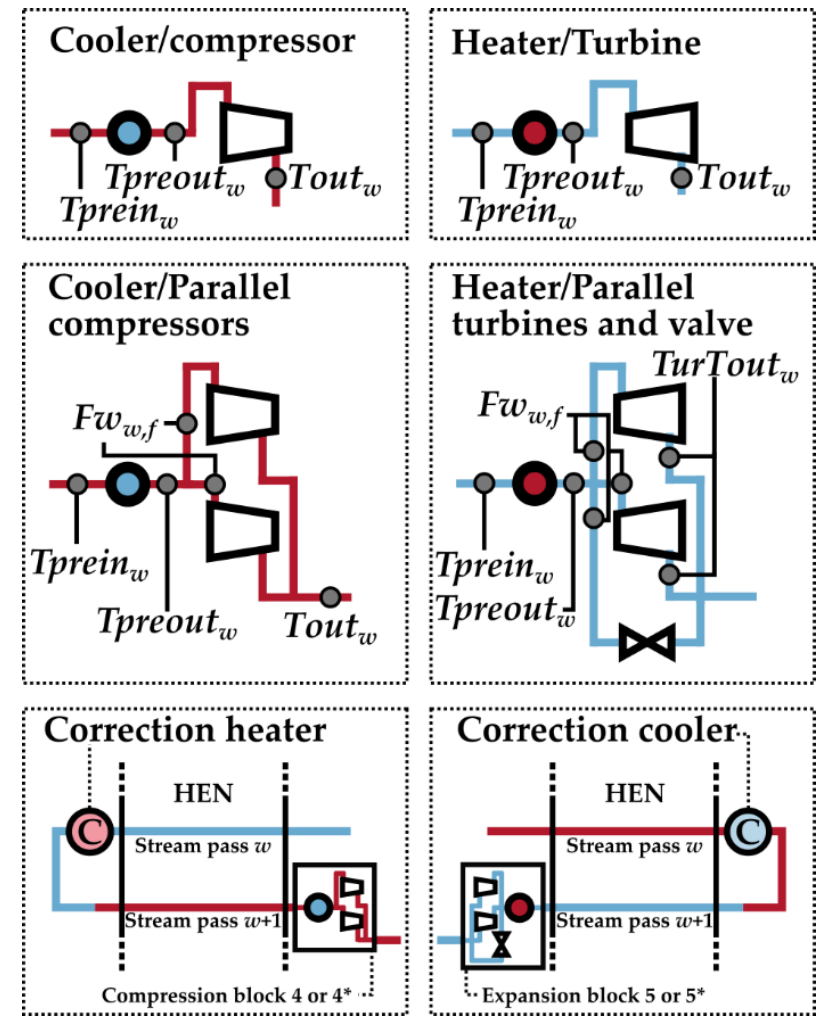

Figure 2. Details of new blocks and associated decision variables

Operating costs $(O C)$ are calculated as follows:

$$
\begin{aligned}
\text { OC }= & \left(\sum_{m \in N H U} \sum_{j \in N C} \sum_{k \in N S} \text { Chu }_{m} \cdot \text { Qhuinter }_{m, j, k}+\sum_{m \in N H U} \sum_{o j \in N O C} \text { hutype }_{m} \text { Chu }_{m} Q h u_{o j}\right)+ \\
& \left(\sum_{i \in N H} \sum_{n \in N C U} \sum_{k \in N S} \text { Ccu }_{n} \cdot \text { Qcuinter }_{i, n, k}+\sum_{n \in N C U} \sum_{o i \in N O H} \text { cutype }_{n} \text { Ccu }_{n} Q c u_{o i}\right)+ \\
& \mathrm{Cel} \cdot\left(\text { TotalCompWork }+\sum_{s \in N S h} \text { SSTCWorkLack }_{S}\right)- \\
& \operatorname{Rel} \cdot\left(\text { TotalTurbWork }+\sum_{s \in N S h} \text { SSTCWorkSurplus }_{S}\right)
\end{aligned}
$$

where $C h u_{m}$ and $C c u_{n}$ are hot and cold utility costs, Qhuinter $_{m, j, k} /$ Qcuinter $_{i, n, k}$ and $Q h u_{o j} / Q c u_{o i}$ are intermediate and final stage heater/cooler heat loads and hutype $e_{m} /$ cutype $_{n}$ are binary variables used to correctly assign operating cost for the use of utility in final stage units. These are parameters/variables related to the heat exchanger network superstructure. Note that intermediate stage heaters/coolers are defined as utility-based temperature manipulation equipment that may be placed at middle points of a given stream, which is a feature of the stage-wise superstructure used here [32] and is an enhancement in comparison to the original stage-wise superstructure of 
Yee and Grossmann [3]. The calculation of heat loads for those units are performed via energy balances, whose derivation may be found in detail in the published literature [31,32]. Cel and Rel are the cost and revenue price of electricity.

Capital costs (CC) are obtained by summing heat exchangers, heaters, coolers, compressors, expansion units (turbines and valves), auxiliary motors and generators costs. Area costs are obtained with capital cost functions of area (AreaCost(area)). These areas are those of heat exchangers $\left(A_{i, j, k}\right)$, intermediate stage (Ahuinter ${ }_{m, j, k} /$ Acuinter $\left._{i, n, k}\right)$ and final-stage heaters/coolers $\left(A h u_{o j} / A c u_{o i}\right)$. Capital costs for pressure manipulation units (CompCost $\left.t_{w, f} / \operatorname{ExpCost}_{w, f}\right)$ are, as in the literature, calculated from functions of either the flowrate or the shaft-works. CC for motors and generators (MotCost $/$ GenCost ${ }_{s}$ ) are functions of shaft-works. All these functions and the required parameters are provided in Section 3 (Numerical Examples).

$$
\begin{aligned}
& C C=\sum_{i \in N H} \sum_{j \in N C} \sum_{k \in N S} \operatorname{AreaCost}\left(A_{i, j, k}\right)+\sum_{i \in N H} \sum_{n \in N C U} \sum_{k \in N S} \operatorname{AreaCost}\left(\text { Acuinter }_{i, n, k}\right) \\
& \left.+\sum_{m \in N H U} \sum_{j \in N C} \sum_{k \in N S} \text { AreaCost(Ahuinter }{ }_{m, j, k}\right) \\
& +\sum_{w \in N G} \operatorname{AreaCost}\left(\operatorname{Acu}_{w}\right)+\sum_{w \in N G} \operatorname{AreaCost}\left(\operatorname{Ahu}_{w}\right) \\
& +\sum_{w \in N G} \operatorname{AreaCost}\left(\text { Apre }_{w}\right)+\sum_{w \in N G} \operatorname{AreaCost}\left(\text { Acor }_{w}\right) \\
& +\sum_{w \in N G} \sum_{f \in N F} \operatorname{CompCost}_{w, f}+\sum_{w \in N G} \sum_{f \in N F} \operatorname{Exp} \operatorname{Cost}_{w, f} \\
& +\sum_{s \in S S} \text { MotCost }_{S}+\sum_{s \in S S} \text { GenCost }_{s}
\end{aligned}
$$

Finally, the optimization problem is formulated as follows:

$$
\begin{array}{cc}
\min & \{T A C=O C+A F \cdot C C\} \\
\text { s.t. } & \text { Eqs. (1) }-(31) \text { and HEN equations }[31,32]
\end{array}
$$

where the total annual costs (TAC) for the WHEN must be minimized and $A F$ is the annualizing factor for capital costs. The objective function is subject to Eqs. (1)-(31) as well as to HENspecific equations [31,32].

\subsection{Solution method remarks}

The solution algorithm used here is based on the Simulated Annealing/Rocket Fireworks Optimization [38] (SA-RFO), which was originally developed for the synthesis of HEN and further re-worked into a WHEN synthesis version [31]. SA-RFO is a two-level optimization method whose "levels", in the latter version, are:

(i) outer level (SA), sequentially proposes new HEN/WHEN topologies by adding/removing temperature/pressure manipulating units; 
(ii) inner level (RFO), optimizes continuous variables associated with the proposed structure (heat loads, stream split fractions and shaft-work rates).

In-depth descriptions of the meta-heuristic concepts behind the methodology are presented in previous works [31,38]. Here, we highlight the main improvements that were carried out in this new version.

In the previous SA-RFO adaptation for WHEN synthesis, all pressure manipulation blocks had shaft-work rates as associated continuous decision variables. From them, all other design aspects were calculated. In some industrial cases, though, rigorous temperature boundaries must be considered in work/heat integration. In letting the algorithm handle shaft-work rate variables, temperatures have to be obtained after some calculation steps. This means that temperature variables had to be handled indirectly after a given shaft-work rate modification. That is, if in a given solution temperature is out of boundaries, that solution should be penalized, and it is thus expected that in further iterations that solution would be led back to a feasible region. That may not be the best approach in all cases. For instance, in the multi-stage, intercooled compression case, with compressions having to operate within a narrow temperature range, it may be difficult to find feasible solutions, given that several units may be simultaneously penalized during the algorithm execution, and stagnation on unfeasible regions may occur.

To better handle this sort of issue, the four new proposed blocks use temperature values as decision variables. Hence, in these blocks, SA-RFO no longer manipulates shaft-works, but calculates them from temperature decision variables. Operating this way, SA-RFO may manipulate temperatures only within their allowable intervals, prior to calculating the whole objective function and thus not relying on penalization functions. Computationally, in a given iteration, this is simply performed as follows for compressors:

$$
\text { if } \begin{aligned}
\text { Tout }_{w} & >\text { TUB } \\
\text { Tout }_{w} & \leftarrow \text { TUB } \\
& \\
\text { if } \quad \text { Tpreout }_{w} & >T L B_{w} \\
\text { Tpreout }_{w} & \leftarrow T L B_{w}
\end{aligned}
$$

And for turbines:

$$
\text { if } \begin{aligned}
\text { Tout }_{w} & <T L B_{w} \\
\text { Tout }_{w} & \leftarrow T L B_{w}
\end{aligned}
$$

Or, in case of parallel turbines:

$$
\text { if } \begin{aligned}
\text { TurTout }_{w} & <T L B_{w} \\
\text { TurTout }_{w} & \leftarrow T L B_{w}
\end{aligned}
$$




$$
\text { if } \begin{aligned}
\text { Tpreout }_{w} & >T U B_{w} \\
\text { Tpreout }_{w} & \leftarrow T U B_{w}
\end{aligned}
$$

Evidently, all the other thermodynamic-related penalty functions described in previous works remain.

For tackling case studies, a simple experimental method is proposed. For each example, the algorithm is applied 20 times. The best solution among these 20 is then used as an initial solution and undergoes a "refinement stage". That is, it is set as an initial solution in the algorithm, which is then executed 10 additional times. The best solution is then reported. The method is performed in parallel using ten processing threads, each executing the algorithm twice in the initial stage and once in the refining stage.

\section{Numerical Examples}

In order to validate the methodology, four case studies are tackled in this section. The first two examples are conceptual case studies from the literature used for optimization benchmarking purposes, while the other two are industrial-based cases whose original proposed designs are compared to those attained by the present methodology. In all cases, three stages were used in the HEN superstructure, and a small value $(1 \mathrm{~K})$ was used for minimal approach temperature (EMAT) so that infinite areas are avoided and, to some extent, provides the algorithm with freedom to find heat exchangers (HE) of all sizes if they are cost-effective and thermodynamically feasible. In cases, two formulations for capital cost are present, which are presented in Table 1. Formulation 1 was proposed by Razib et al. [23]. Formulation 2 is the same formulation used by Pavão et al. [31,39], with exception of CC for heat exchangers. The equation used in those works was a second-order polynomial approximation (R-squared of 0.997) of that from Turton et al. [40]. The latter contained logarithmic terms, which add some computing complexity due to its nonlinearity. Here, the same equation is approximated linearly, which still yields good accuracy (R-squared of 0.994). All optimization tests were performed in a computer with an Intel ${ }^{\circledR}$ Core $^{\mathrm{TM}}$ i7-8750H CPU @ 2.20 GHz and 8.00 GB of RAM.

\begin{tabular}{|c|c|c|}
\hline Cost function & Formulation 1 & Formulation 2 \\
\hline HE (\$) & $3000+30$ (Area) & $71,337.07+747.9931$ (Area) \\
\hline Compressor (\$) & $250,000+1000(C P)$ & $51,104.85(\text { Work })^{0.62}$ \\
\hline SSTC compressor (\$) & $50,000+1000(C P)$ & $51,104.85(\text { Work })^{0.62}-985.47(\text { Work })^{0.62}$ \\
\hline Turbine (\$) & $200,000+1000(C P)$ & $2585.47(\text { Work })^{0.81}$ \\
\hline SSTC turbine (\$) & $40,000+1000(C P)$ & $2585.47(\text { Work })^{0.81}-985.47(\text { Work) })^{0.62}$ \\
\hline Auxiliary motor/generator (\$) & $2,000+1000($ Work $)$ & $985.47(\text { Work })^{0.62}$ \\
\hline Valve (\$) & $2,000+1000(C P)$ & 104.0 \\
\hline Annualizing factor $\left(\mathrm{y}^{-1}\right)$ & - & 0.18744 \\
\hline
\end{tabular}

Table 1. Capital cost functions for different units 


\subsection{Example 1}

This case study was proposed by Huang and Karimi [28] and comprises one hot and one cold constant-pressure streams and one HP-hot and one LP-cold streams. Stream data is presented in Table 2. It is worth noting that, in general, it is convenient to consider LP streams as hot ones, since pre-cooling may lead to lower shaft-work requirements in the compressors, and in many cases serial compressors may require intercooling. Conversely, for HP streams, heating prior to expansion may lead turbines to produce more shaft-work. Since in this example the LP stream final temperature is required to be higher than its initial one, and for the HP the opposite occurs, the authors demonstrate some capabilities of their MINLP model that are particularly useful in such a scenario. Namely, one of these features is the flexibility for using either a heater or a cooler to correct stream final temperatures. Huang and Karimi [28] considered the LP stream as a hot one for allowing some cooling prior to the compressor (and thus reduce the shaft-work rate required in that unit), but they could also set the final temperature correction unit was a heater, instead of a cooler. The opposite occurred in the HP stream, which was classified as a cold one. Another feature of this case is that the LP stream operates in above-ambient conditions. In this case, compression may lead streams to undesirably high temperatures, and thus sets of compressors with intercooling may be required.

Firstly, for fair benchmarking purposes, this case is evaluated as proposed by Huang and Karimi [28], without considering practical temperature boundaries (Case 1). The solution found by those authors has a compressor with a discharge temperature of $649.4 \mathrm{~K}$, which is higher than the maximum discharge temperature considered in this work (463.71 K [36]). The solution found by the present method for Case 1 also has a high discharge temperature in the compressor (649.6 K), but has some structural differences in comparison to Huang and Karimi’s [28].

Only one heat exchanger is used in the present solution, matching streams 1 and 2. This heat exchange is performed prior to both heater and turbine in stream 1 . The heating in stream 4 is performed totally by means of hot utility. Despite not involving all streams and having one less heat exchanger, the total heat recovery of the WHEN is the same as in the literature [28] solution $(100.0 \mathrm{~kW})$. Another difference regards the valve placement. In Huang and Karimi's solution, the valve is placed at the end of stream 1 . In the present solution, that stream is split into two substreams, one passing through a turbine and the other through a valve. The solution presented here for Case 1 is depicted in Figure 3a and has TAC of 171,962, which is 1.5\% lower than that associated with the solution identified by Huang and Karimi [28].

In a second experiment (Case 2), this case is evaluated considering realistic temperature bounds and a maximum of three-units per coupling. The solution found in this scenario is presented in Figure 3b. It can be noted that the compression task is performed in two stages. Between the compressors, the LP stream is cooled down by passing through two heat exchangers and one 
cooler. Then, a heater downstream increases the LP stream temperature to its target value. As in Case 1, the expansion task is carried out by a turbine and a valve placed in parallel, but no preheating device is used. Given the need for additional cooling and an extra compressor, this solution presents considerably higher TAC. A comparison with the literature solution regarding several design features is presented in Table 3. The total execution time for this example was around 40 minutes for each case.

Table 2. Stream data for Example 1

\begin{tabular}{|c|c|c|c|c|c|c|c|}
\hline Stream & Type & Tsupply (K) & Ttarget (K) & $\begin{array}{l}\text { psupply } \\
\text { (MPa) }\end{array}$ & $\begin{array}{l}\text { ptarget } \\
\text { (MPa) }\end{array}$ & $\mathrm{CP}(\mathrm{kW} / \mathrm{K})$ & $\begin{array}{l}\mathrm{h} \quad\left(\mathrm{kW} /\left(\mathrm{m}^{2} .\right.\right. \\
\mathrm{K}))\end{array}$ \\
\hline 1 & HP/Hot & 400 & 320 & 0.5 & 0.1 & 3.0 & 0.1 \\
\hline 3 & Hot & 550 & 450 & - & - & 1.0 & 0.1 \\
\hline 2 & LP/Cold & 410 & 660 & 0.1 & 0.5 & 2.0 & 0.1 \\
\hline \multirow[t]{3}{*}{4} & Cold & 320 & 350 & - & - & 2.0 & 0.1 \\
\hline & $\mathrm{HU}$ & 680 & 680 & - & - & - & 1.0 \\
\hline & CU & 300 & 300 & - & - & - & 1.0 \\
\hline \multicolumn{8}{|c|}{ Cel = $960 \$ / \mathrm{kWy} ; R e l=800 \$ / \mathrm{kWy} ; C h u=280$ \$/kWy; Ccu = 8 \$/kWy; } \\
\hline \multicolumn{8}{|c|}{$\eta_{c}=\eta_{t}=1.0 ; \kappa=1.4 ; \mu=1.961 \mathrm{~K} / \mathrm{MPa}$} \\
\hline
\end{tabular}

Table 3. Results for Example 1

\begin{tabular}{|c|c|c|c|}
\hline & Huang and Karimi [28] & This work (Case 1) & This work (Case 2) \\
\hline Recovered work (kW, via WEN) & 478.7 & 479.3 & 362.7 \\
\hline Recovered heat (kW, via HEN) & 100.0 & 100.0 & 283.2 \\
\hline Compression work (kW) & 478.7 & 479.3 & 362.7 \\
\hline Expansion work (kW) & 478.7 & 479.3 & 362.7 \\
\hline Heating (kW) & 220.1 & 220.2 & 327.2 \\
\hline Cooling (kW) & 0.0 & 0.0 & 106.6 \\
\hline Heaters & 2 & 3 & 1 \\
\hline Coolers & 0 & 0 & 1 \\
\hline Heat exchangers & 2 & 1 & 3 \\
\hline Compressors (in SS) & $1(1)$ & $1(1)$ & $2(2)$ \\
\hline Turbines (in SS) & $1(1)$ & $1(1)$ & $1(1)$ \\
\hline Helper motors & 0 & 0 & 0 \\
\hline Helper generators & 0 & 0 & 0 \\
\hline Valves & 1 & 1 & 1 \\
\hline Shafts & 1 & 1 & 1 \\
\hline TAC (\$/y) & 174,560 & 171,962 & 271,358 \\
\hline
\end{tabular}



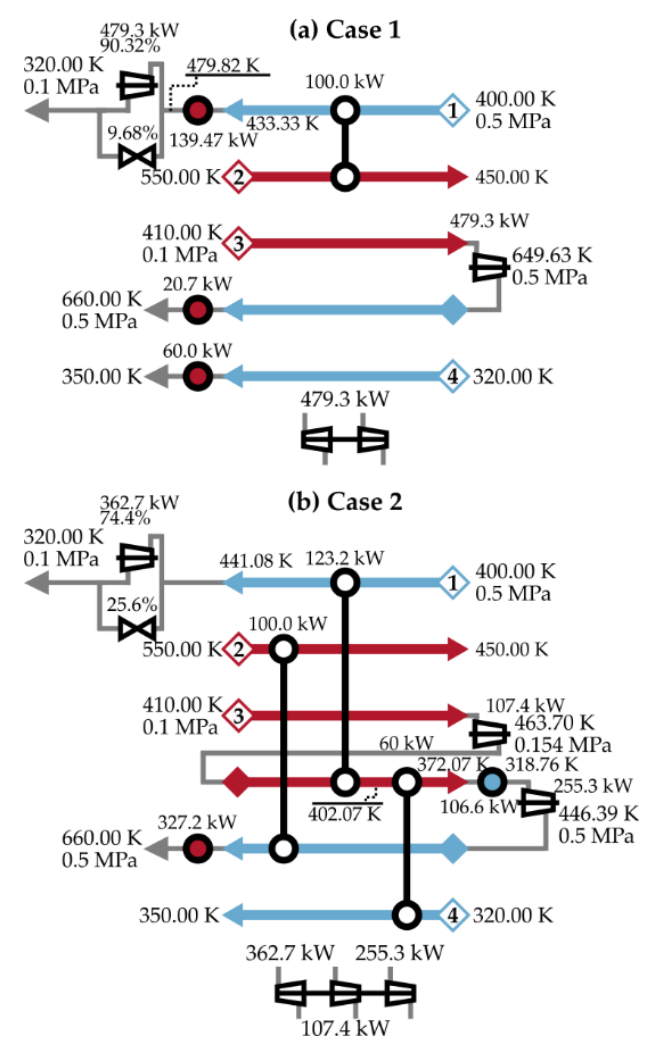

Figure 3. Solutions for Example 1 (a) Case 1 and (b) Case 2

\subsection{Example 2}

This example was proposed by Onishi et al. [26] and only has isothermal streams, being two lowand three high-pressure ones. It is an above-ambient temperature process (temperatures up to 420 $\mathrm{K}$ ) and for that reason, in special, compression may rise stream temperatures to undesirably high values. Hence, multi-stage compression with intercooling should be considered, which makes this example an interesting test for the present methodology. The case is studied here under the formulation of the same cost used by Huang and Karimi [28] (see Formulation 1 in Table 1). Those authors have applied such a formulation to perform a benchmark test comparing their model versus Onishi et al.'s [26]. For that reason, that formulation is also used here for a fair comparison to the literature solutions.

As demonstrated by Huang and Karimi, in this case, it is advantageous to maximize shaft-work in the turbines. In that situation, it may be convenient to use pre-heating in those units. Performing expansion tasks at such high temperatures may lead HP streams to require some cooling postexpansion. For that reason, HP streams that pass through the HEN region are modeled as follows: two cold passes, each with a parallel expansion unit in the WEN stage (two turbines and one valve), one hot pass with a temperature correction unit in the end with target temperature equal to the original stream temperature and one cold pass with a final heater unit. It is worth noting that if the temperature is lower than the target temperature in the corrector cooler, that unit is 
omitted and then the final heater (or heat exchangers) takes place in the final cold pass, heating the streams to the final temperature.

For fair benchmarking, this case was firstly approached without considering either coupling constraints (i.e., any number of compressors/turbines may be coupled) or the practical temperature boundaries proposed in this work for compressor/turbines (Case 1). A second study was performed considering coupling between a maximum of three units per shaft (plus a possible helper motor/generator) as well as the temperature constraints (Case 2).

The solution found for Case 1 has a lower TAC than those presented in the literature $(4.3 \%$ reduction in comparison to the solution identified by Huang and Karimi's [28] model). That was achieved essentially due to the greater work recovery $(14,832 \mathrm{~kW})$ obtained via SSTC. Due to pre-heating, all expansion processes were performed at high temperatures, increasing the total shaft-work generated in the turbines. Moreover, only three heat exchangers were necessary, rendering a simpler HEN than in previous designs.

The constrained solution (Case 2) also outperforms previous literature solutions (3.1\%). An interesting feature of this solution is that it required five shaft couplings. Four of the couplings have one compressor and one turbine, while one has two turbines coupled to one compressor. The method placed compressors and turbines in such a manner that no helper motor/generator was necessary when coupling those units. The high-temperature expansion played fundamental role here for increasing shaft-work production, as in Case 1. Regarding compressors, temperature and coupling constraints led to the presence of units both in series and in parallel. Each of the solutions was obtained in about 1.5 hours. They are compared to the literature solutions in Table 5 and are illustrated in Figure 4.

Table 4. Stream data for Example 2

\begin{tabular}{|c|c|c|c|c|c|c|c|}
\hline Stream & Type & Tsupply (K) & Ttarget (K) & psupply (MPa) & ptarget (MPa) & $\mathrm{CP}(\mathrm{kW} / \mathrm{K})$ & $\mathrm{h}\left(\mathrm{kW} /\left(\mathrm{m}^{2} \cdot \mathrm{K}\right)\right)$ \\
\hline 1 & LP & 390 & 390 & 0.1 & 0.7 & 36.81 & 0.1 \\
\hline 2 & LP & 420 & 420 & 0.1 & 0.9 & 14.73 & 0.1 \\
\hline 3 & HP & 350 & 350 & 0.9 & 0.1 & 21.48 & 0.1 \\
\hline 4 & HP & 350 & 350 & 0.85 & 0.15 & 25.78 & 0.1 \\
\hline \multirow[t]{3}{*}{5} & HP & 400 & 400 & 0.7 & 0.2 & 36.81 & 0.1 \\
\hline & $\mathrm{HU}$ & 680 & 680 & - & - & - & 1.0 \\
\hline & $\mathrm{CU}$ & 300 & 300 & - & - & - & 1.0 \\
\hline \multicolumn{8}{|c|}{$\mathrm{Cel}=960 \$ / \mathrm{kWy} ; \mathrm{Rel}=800 \$ / \mathrm{kWy} ;$ Chu = 280 \$/kWy; Ccu = 8 \$/kWy; } \\
\hline \multicolumn{8}{|c|}{$\eta_{c}=\eta_{t}=0.7 ; \kappa=1.4 ; \mu=1.961 \mathrm{~K} / \mathrm{MPa}$} \\
\hline
\end{tabular}

Table 5. Results for Example 2

\begin{tabular}{lllll}
\hline & $\begin{array}{l}\text { Huang and Karimi [28] } \\
\text { with Onishi et al.'s [26] }\end{array}$ & Huang and Karimi [28] & This work (Case 1) & This work (Case 2) \\
& model & & & \\
\hline $\begin{array}{l}\text { Recovered work (kW, via } \\
\text { WEN) }\end{array}$ & 10,474 & 11,579 & 14,832 & 14,720 \\
\hline
\end{tabular}




\begin{tabular}{lllll}
\hline Recovered heat (kW, via & 7188 & 8663 & 10,227 & 10,002 \\
HEN) & & 19,314 & 18,806 & 18,803 \\
Compression work (kW) & 19,314 & 11,579 & 14,832 & 13,378 \\
Expansion work (kW) & 10,474 & 5276 & 14,947 & 14,745 \\
Heating (kW) & 1680 & 13,010 & 18,922 & 18,834 \\
Cooling (kW) & 10,520 & 3 & 4 & 5 \\
Heaters & 1 & 6 & 9 & 8 \\
Coolers & 4 & 6 & 3 & 5 \\
Heat exchangers & 7 & $4(3)$ & $4(3)$ & $6(5)$ \\
Compressors (in SS) & $5(3)$ & $3(3)$ & $6(6)$ & $6(6)$ \\
Turbines (in SS) & $3(3)$ & 0 & 0 & 0 \\
Helper motors & 0 & 0 & 0 & 0 \\
Helper generators & 0 & 0 & 0 & 1 \\
Valves & 1 & 1 & 1 & 5 \\
Shafts & 1 & $10,186,680$ & $9,752,857$ & $9,873,282$ \\
TAC (\$y) & $10,501,849$ & & & \\
\hline
\end{tabular}
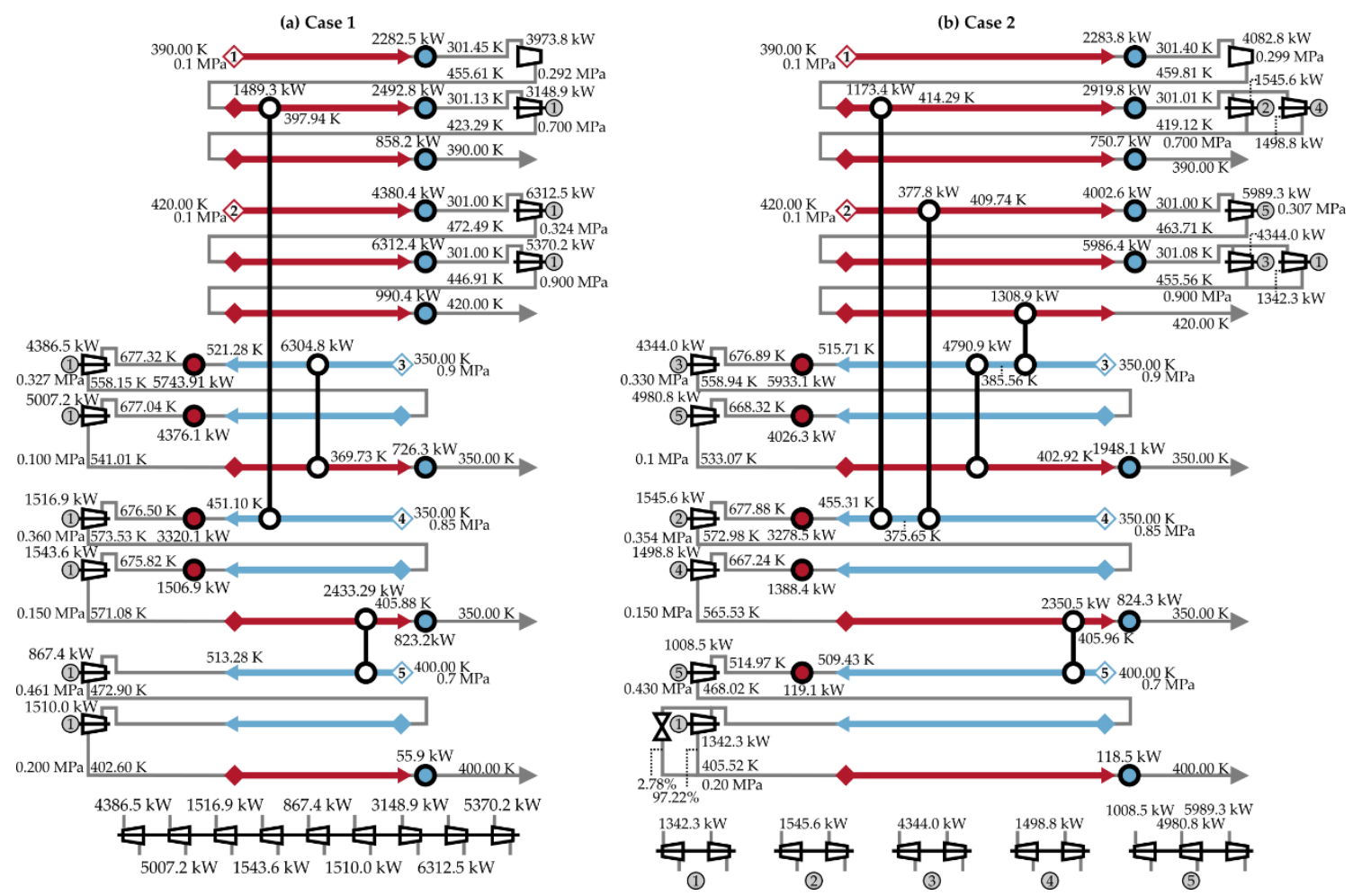

Figure 4. Solutions for Example 2 (a) Case 1 and (b) Case 2

\subsection{Example 3}

This case study was proposed by Fu and Gundersen [41] and the streams involved are part of a membrane separation process of air in oxy-combustion processes. In order to model this as a work and heat integration case study, those authors considered the oxy-combustion process with oxygen supply using an Ion Transport Membrane (ITM), as described in Ref. [42]. This process design comprises the four-stage compression with intercooling of ambient air, the further heating 
of that stream in a natural gas combustor unit and finally the oxygen separation via ITM. The $\mathrm{N}_{2}$ that is separated from the air in the ITM is at $800{ }^{\circ} \mathrm{C}$ and 14 bar and is available for utilization in pre-heating the air stream as well as for expansion for power recovery. Fu and Gundersen [41] investigated this case aiming mainly for the reduction of energy requirements. The solution proposed by those authors employs a one-stage compression process for the air stream with a $426.4{ }^{\circ} \mathrm{C}(699.55 \mathrm{~K})$ discharge temperature, which greatly reduces the heating requirements in the process.

The study performed here adapts the base case proposed by Fu and Gundersen [41]. The streams considered are presented in Table 6. The maximum operating temperature for compressors assumed here is $375^{\circ} \mathrm{F}$ (463.71 K) [36], which is lower than the $500^{\circ} \mathrm{C}(773.15 \mathrm{~K})$ limit imposed by Fu and Gundersen [41]. Turbines may operate with temperatures up to $1000{ }^{\circ} \mathrm{F}(810.93 \mathrm{~K})$ [36]. It is thus expected that multi-stage compression is required. Couplings were allowed between two units (plus a motor/generator). The maximum compressor/turbine shaft-work rate was considered as $10 \mathrm{MW}$. Monetary values are associated to design features (capital and operating costs), so that a costs-driven optimization can be performed. The capital cost parameters used are those from "Formulation 2" (Table 1). The hot utility cost was assumed as the natural gas cost for Feb. 2019, obtained from the US Energy Information Administration [43]. Electricity price for the industrial sector was obtained from the same source. Cooling costs were calculated as proposed by Turton et al. [40] (Examples 8.3 and 8.5). Capital costs for the natural gas combustor were not considered, as it was assumed as a constant-size unit.

It is interesting to note that the HP stream's initial temperature is higher than the proposed maximum operating temperature for turbines. Hence, this stream was modeled with a first pass through the heat recovery region with identification as hot stream and with a temperature correction unit (cooler, see Eq. (30)) for ensuring the turbine inlet temperature is always lower than its upper bound.

The method found a solution with a three-stage compression with intercooling, one heat exchanger and two sets of parallel turbines (two in each set). Three turbine/compressor couplings were performed, with one requiring a helper generator. One standalone turbine is also present in the solution. It is worth noting that the identified solution is sustainable regarding power, even with some surplus quantity being sold. This is due to the fact that electricity use represents larger expenses than utilities, and since this is a costs-driven design procedure, a solution with lower electricity requirements than those presented in the literature was identified. Moreover, it is worth noting that all operating temperatures are within the preset practical thresholds. The TAC of this solution is of 15,306,207 \$/y, being 11,619,439 \$/y of capital costs, 4,501,132 \$/y of operating costs and an income of $814,364 \$ / y$ from electricity sales. The solution was obtained by our method in about one hour. 
Since the criteria used to develop the designs presented in this work differ from those of the literature, Table 7 presents the comparison among some important aspects of each configuration not regarding costs. The design is presented in Figure 5. As in the other solutions, one heat exchanger is placed for heat recovery between post-compression stream 2 and pre-expansion stream 1. Notable differences are observed regarding energy requirements. Since in this work electricity is more expensive than utilities, the methodology identified a solution with low compression work and high expansion work. Heating is not as expensive as electricity, and our solution has the highest requirement. On the other hand, cooling requirement is lower in the multistage compression of the original ITM (the value of cooling was estimated from the pressure/temperatures presented by Fu and Gundersen [41] for the original ITM [42]). Fu and Gundersen's design has no cooling requirement since a single-stage compression was considered. It is not possible to state whether a solution is better than the others, given that different criteria were considered in the respective methodologies. Electricity and utility costs may vary according to a series of factors, e.g., electricity or fuel sources in the region of the plant. Should, for instance, higher costs be associated to hot utilities, the present methodology would likely seek for solutions that are more similar to Fu and Gundersen's design, reducing natural gas needs.

Table 6. Stream data for Example 3

\begin{tabular}{|c|c|c|c|c|c|c|c|}
\hline Stream & Type & Tsupply (K) & Ttarget (K) & $\begin{array}{l}\text { psupply } \\
\text { (MPa) }\end{array}$ & $\begin{array}{l}\text { ptarget } \\
(\mathrm{MPa})\end{array}$ & $\mathrm{CP}(\mathrm{kW} / \mathrm{K})$ & $\begin{array}{l}\text { h }\left(\mathrm{kW} /\left(\mathrm{m}^{2} \cdot\right.\right. \\
\mathrm{K}))\end{array}$ \\
\hline 1 & $\mathrm{HP} / \mathrm{Hot}$ & 1073.15 & - & 1.4 & 0.1 & 83.7 & 0.1 \\
\hline \multirow[t]{3}{*}{2} & LP/Cold & 288.15 & 1073.15 & 0.1 & 1.4 & 100.0 & 0.1 \\
\hline & $\mathrm{HU}$ & 680 & 680 & - & - & - & 1.0 \\
\hline & $\mathrm{CU}$ & 300 & 300 & - & - & - & 1.0 \\
\hline \multicolumn{8}{|c|}{ Cel = 550.4 \$/kWy; Rel = $440.32 \$ / \mathrm{kWy} ;$ Chu = 73.43 \$/kWy; Ccu = $182.14 \$ / \mathrm{kWy}$} \\
\hline \multicolumn{8}{|c|}{$\eta_{c}=\eta_{t}=0.80 ; \kappa=1.4 ; \mu=1.961 \mathrm{~K} / \mathrm{MPa}$} \\
\hline
\end{tabular}

Table 7. Results for Example 3

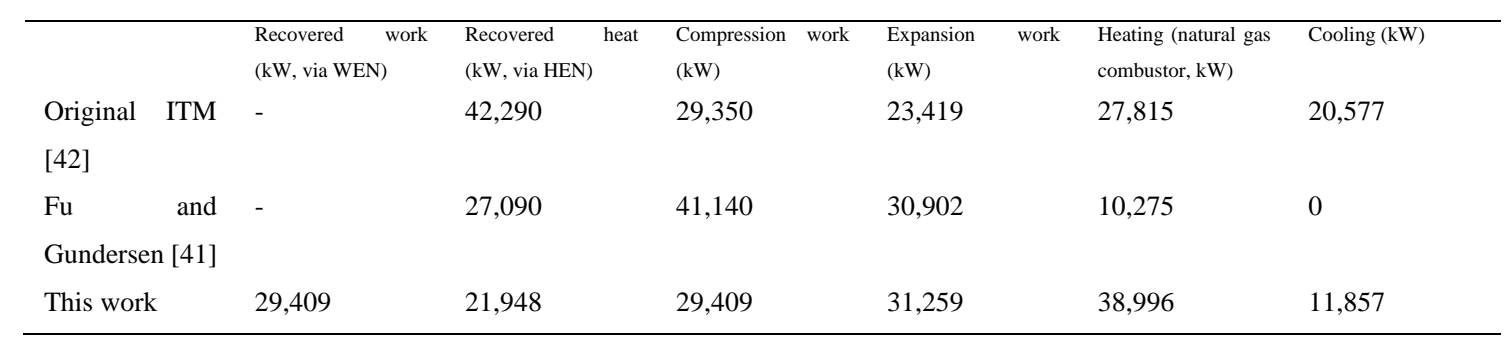




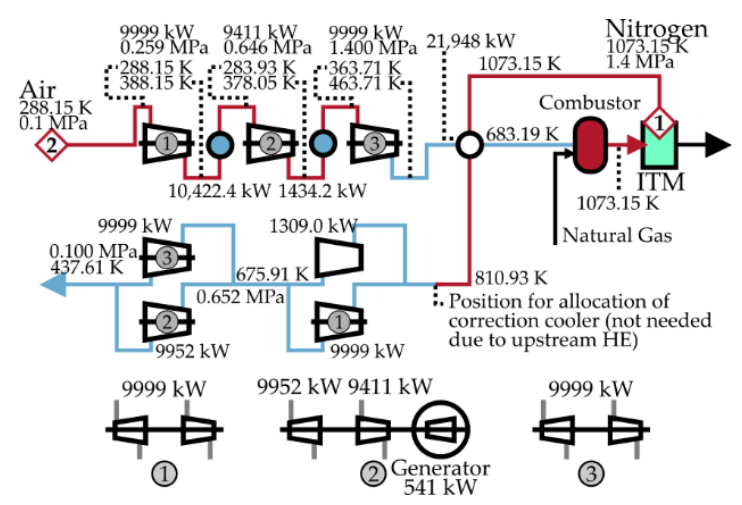

Figure 5. Solution for Example 3

\subsection{Example 4}

This example is based on the ammonia plant sample design from the Aspen Plus ${ }^{\circledR}$ software [37]. The simulation comprises the production of ammonia from natural gas. Among the simulation material streams, six were considered and modelled here as a work and heat integration case study. Streams are presented in Table 8. All enthalpy-related data were obtained from data sets generated for temperature/pressure operating ranges of each stream with Aspen Plus ${ }^{\circledR}$ using the PengRobinson equation of state. For most streams, temperature/enthalpy relations were nearly linear with little variation over the operating pressure ranges, so constant heat capacities could be considered with good accuracy. Stream \#2 operating temperature range involves phase-change. Hence, a piecewise linear function was used for accuracy (see Pavão et al. [33] for detailed comments on heat exchanger sizing considering piecewise linear functions).

Stream \#1 is the outlet stream from the methanation unit, which needs to be cooled down and compressed for later use in the synthesis unit. Stream \#2 is the post-synthesis, ammonia-rich stream, which has already passed through a water heat exchanger for producing steam. Even after such heat exchange process, this stream still requires cooling. Stream \#3 is the pre-synthesis stream which requires some compression and heating towards reaction-optimal conditions. Stream \#4 is the process purge stream, which, despite its low flowrate value, is at high pressure and may provide some shaft-work through expansion. We choose to expand this stream to $30 \mathrm{bar}$ (3 $\mathrm{MPa}$ ), which is equal to the pressure of a secondary purge stream in the process. At the same pressure these streams may be mixed and are suitable for a purge gas recovery process such as Pressure Swing Adsorption, which operates at pressures lower than $5 \mathrm{MPa}$ [44]. A target temperature was not specified for this stream. Stream \#5 is the process air stream, which is fed into the reforming process. It requires compression and heating. As in the simulation, after compression, we enforce this stream to be heated to its target temperature by flue gas, whose costs are assumed as in Example 3. Stream \#6 is the stream prior to the methanation process, which, in the simulation, is heated via utility. 
Besides flue gas for Stream \#5, no other utilities are specified by the simulation. Even without such specification, it is interesting that some hypothetical monetary value is associated to utility requirements and heater/cooler areas, so that the optimization approach may attempt to reduce such needs, seeking for less expensive solutions. Note also that modern ammonia plants may even be considered self-sufficient regarding heating and power requirements [44]. Thus, even though the methodology attempts to minimize TAC, we may interpret an optimal result here as a solution with potential "highest-savings" rather than "lowest-costs".

High-pressure steam (at $583.15 \mathrm{~K}, 10 \mathrm{MPa}$ ) was considered as standard hot utility, whose energetic costs $(\$ / \mathrm{kWy})$ were calculated from the combustion process of natural gas at $80 \%$ efficiency. The standard cold utility was assumed as a $-20{ }^{\circ} \mathrm{C}$ refrigerant, and had its costs calculated as proposed by Turton et al. [40] (Example 8.4). The best solution found by our method has TAC of 31,380,058 \$/y, being 12,168,772 \$/y of capital costs and 19,211,286 \$/y of operating costs. The design proposed here presents notable improvements regarding the use of energy, as observed in Table 9. More heat recovery is performed than in the original simulation. Compression work, as well as heating and cooling requirements, is reduced. It can also be observed that some work is now produced with the allocation of a turbine at the purge stream. The design identified by the algorithm is presented in Figure 6. The total execution time was of around 2 hours.

Table 8. Stream data for Example 4

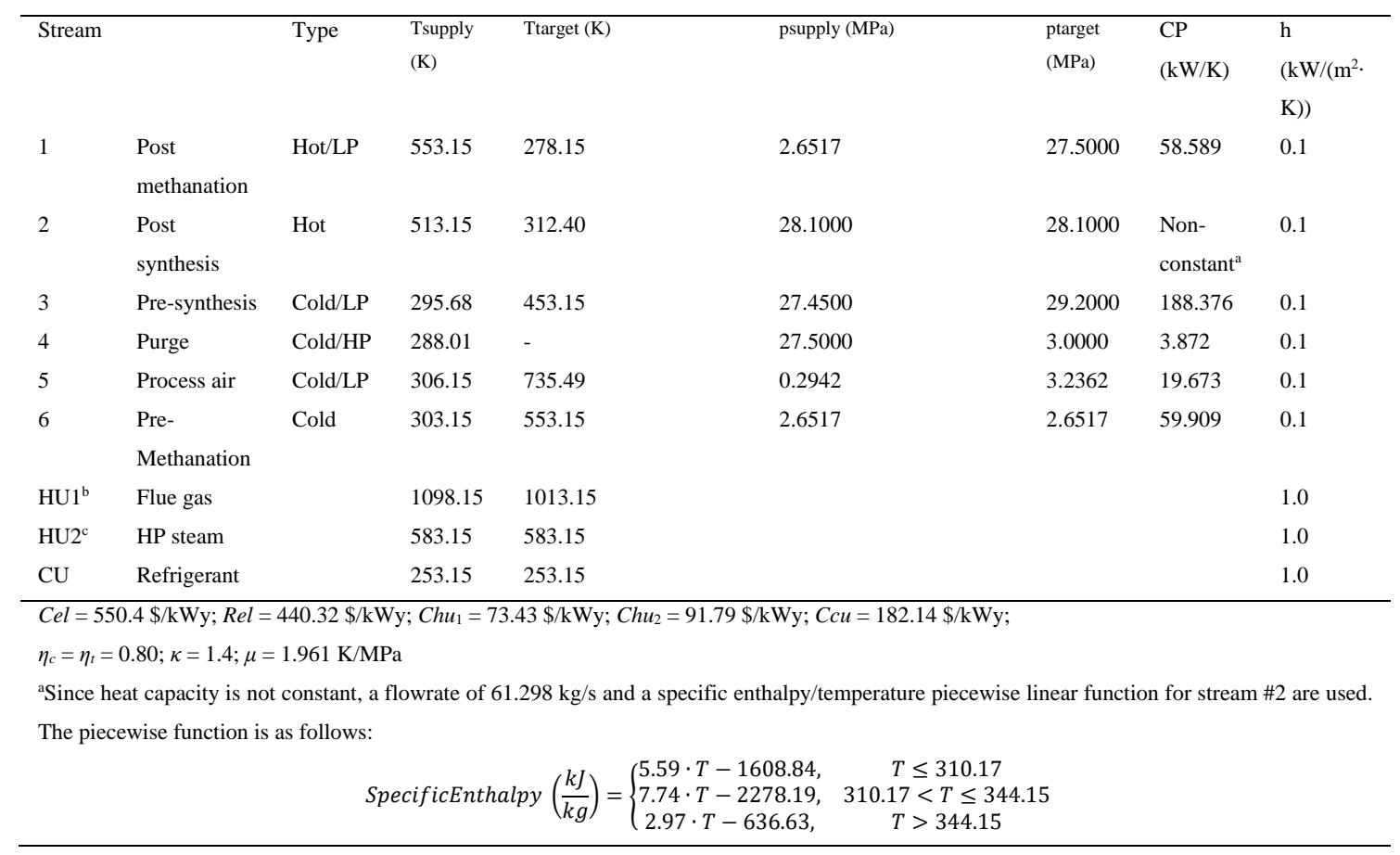

Table 9. Results for Example 4

$\begin{array}{llllllll}\text { Recovered } & \text { Recovered } & \text { Compressio } & \text { Expansion } & \text { Heating via } & \text { Heating via } & \text { Cooling } \\ \text { work } \quad(\mathrm{kW}, & \text { heat } \quad(\mathrm{kW}, & \mathrm{n} \text { work }(\mathrm{kW}) & \text { work }(\mathrm{kW}) & \text { HU1 }(\mathrm{kW}) & \text { HU2 }(\mathrm{kW}) & (\mathrm{kW}) \\ \text { via WEN) } & \text { via HEN) } & & & & & & \end{array}$




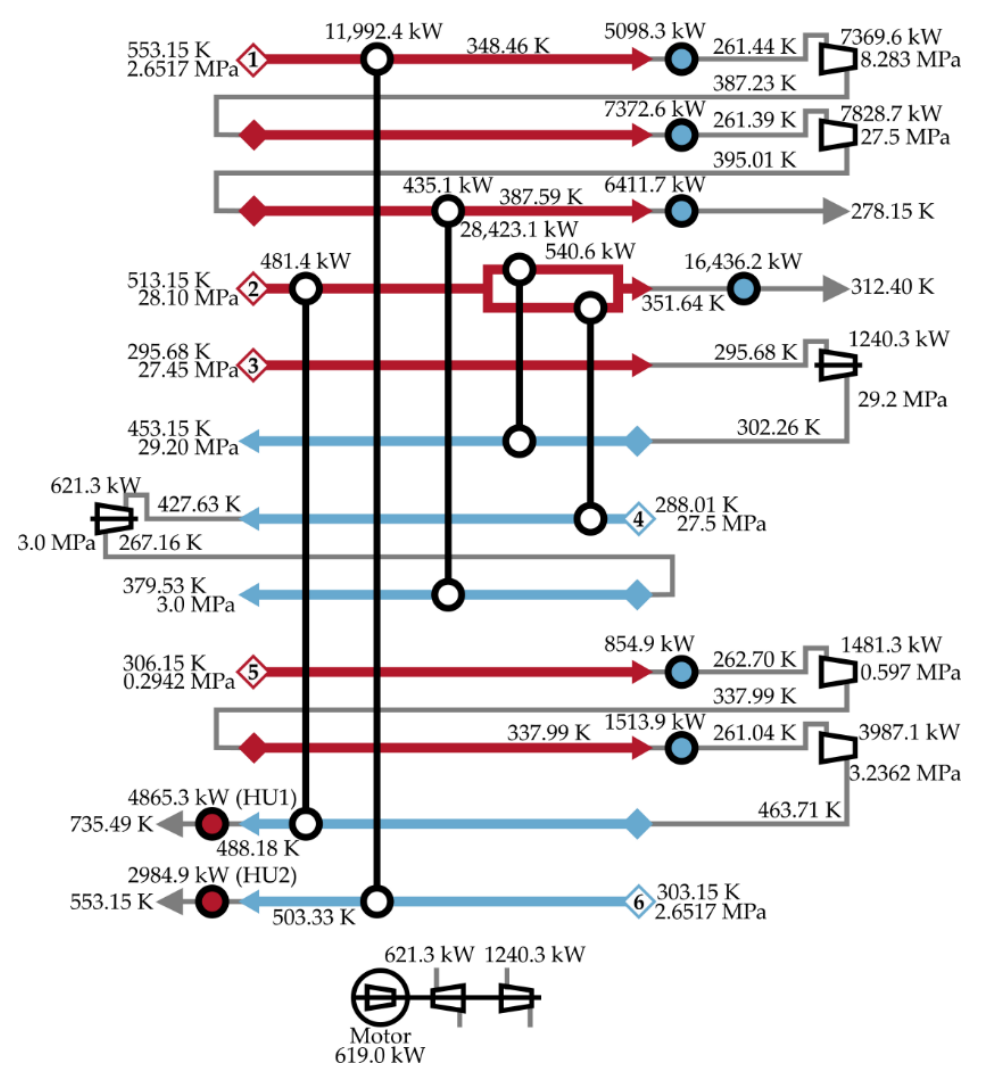

Figure 6. Solution for Example 4

\section{Conclusions}

A new method for performing the synthesis of work and heat exchange networks considering industrial-like constraints was developed. The strategy, based on the use of calculation blocks using inlet temperatures and outlet temperatures as decision variables was able to handle narrow operating condition ranges, especially in compression processes. Moreover, the use of precoolers/pre-heaters prior to compressors/turbines was able to reduce/increase shaft-work requirement/generation. These new blocks were included in a revamped version of a metaheuristic-based framework. The economic and energetic advantages were demonstrated in four numerical examples. Examples 1 and 2 were tackled considering or not these constraints, for benchmarking. In the latter case, simpler configurations than those reported in the literature were found, with fewer heat exchanger units and different positions for pressure manipulation units, and lower total annual costs. It was also shown in these two first examples that when synthesizing WHEN with more practical operating temperature ranges and SSTC couplings, more complex structures might be needed, which the algorithm was able to propose. In Examples 3 and 4, 
industrial process streams were considered for work and heat integration and efficient WHENs were synthesized with reduced energy demands in comparison to original designs. It can be concluded that the method may be used as an efficient tool at early plant design stages for performing efficient work and heat integration.

It is evident that, as for HEN synthesis, the design of efficient WHEN demonstrates great potential for economic and energetic savings. It is, however, an even more challenging task. Future work may aim at the development of more efficient optimization strategies, the use of more accurate thermodynamic relations in sizing units, as well as the association of other criteria in work and heat integration, such as environmental impacts evaluation.

\section{Acknowledgements}

The authors acknowledge the financial support from the National Council for Scientific and Technological Development - Processes 150500/2018-1 and 305055/2017-8 - CNPq (Brazil) and the Coordination for the Improvement of Higher Education Personnel - Processes 88887.360812/2019-00 and 88881.171419/2018-01- CAPES (Brazil).

\section{Nomenclature}

Variables

A

Acor

Acu

Acuinter

Ahu

Ahuinter

Apre

CC

CompCost

ComWork

cutype

ExpCost

$\mathrm{Fw}$

GenCost

hutype

LMTDpre

MotCost

NetWork

OC

ParWork

pin
Heat exchanger area $\left[\mathrm{m}^{2}\right]$

Correction heater/cooler area $\left[\mathrm{m}^{2}\right]$

Final cooler area $\left[\mathrm{m}^{2}\right]$

Intermediate stage cooler area $\left[\mathrm{m}^{2}\right]$

Final heater area $\left[\mathrm{m}^{2}\right]$

Intermediate stage heater area $\left[\mathrm{m}^{2}\right]$

Pre-heater/pre-cooler area $\left[\mathrm{m}^{2}\right]$

Capital costs [\$]

Compressor cost [\$]

Total compression shaft-work at a given shaft [kW]

Binary variable denoting if a particular cold utility type is employed [-]

Expansion unit cost [\$]

Stream split fraction in parallel compression/expansion stage [-]

Generator cost [\$]

Binary variable denoting if a particular hot utility type is employed [-]

Logarithmic mean temperature difference in pre-heaters/pre-coolers [K]

Helper motor cost [\$]

Net shaft-work at a given shaft [kW]

Operating costs $[\$ / y]$

Shaft-work in parallel compressor/turbine [kW]

Pressure manipulation unit inlet pressure [MPa] 


\begin{tabular}{|c|c|}
\hline pout & Pressure manipulation unit outlet pressure [MPa] \\
\hline Qcor & Heat load in correction heater/cooler $[\mathrm{kW}]$ \\
\hline Qcu & Available heat in the end of an original hot stream [kW] \\
\hline Qcuinter & Heat load of an intermediate stage cooler [kW] \\
\hline Qhu & Required heat in the end of an original cold stream [kW] \\
\hline Qhuinter & Heat load of an intermediate stage heater $[\mathrm{kW}]$ \\
\hline Qpre & Heat load in pre-heater/pre-cooler [kW] \\
\hline SSTC & Vector for unit identification as SSTC unit [-] \\
\hline SSTCWorkSurplus & Work rate excess in single-shaft units [kW] \\
\hline SSTCWorkLack & Work rate lack in single-shaft units [kW] \\
\hline TAC & Total annual cost $[\$ / y r]$ \\
\hline Tcorin & Process stream inlet temperature in correction heater/cooler [kW] \\
\hline Tcorout & Process stream outlet temperature in correction heater/cooler [kW] \\
\hline Tin & Pressure manipulation unit inlet temperature [K] \\
\hline TotalCompWork & Total compressor work rate $[\mathrm{kW}]$ \\
\hline TotalTurbWork & Total turbine work rate [kW] \\
\hline Tout & Pressure manipulation unit outlet temperature $[\mathrm{K}]$ \\
\hline Tprein & Process stream inlet temperature in pre-heater/pre-cooler [kW] \\
\hline Tpreout & Process stream outlet temperature in pre-heater/pre-cooler [kW] \\
\hline Trevout & Outlet temperature in reversible process $[\mathrm{K}]$ \\
\hline TurTout & Outlet temperature from parallel turbines $[\mathrm{K}]$ \\
\hline TurWork & Total expansion shaft-work at a shaft [kW] \\
\hline ValTout & Outlet temperature from parallel valve $[\mathrm{K}]$ \\
\hline Work & $\begin{array}{l}\text { Work rate produced/required in a turbine/compressor or energy loss in } \\
\text { valves }[\mathrm{kW}]\end{array}$ \\
\hline \multicolumn{2}{|l|}{ Parameters } \\
\hline$A F$ & Annualizing factor $\left[\mathrm{y}^{-1}\right]$ \\
\hline Aux & Binary vector for unit identification as auxiliary unit [-] \\
\hline Сси & Cold utility cost $[\$ /(\mathrm{kWy})]$ \\
\hline Cel & Electricity cost $[\$ / k W]$ \\
\hline Chu & Hot utility cost $[\$ /(\mathrm{kWy})]$ \\
\hline$C P$ & General process stream total heat capacity flowrate $\left[\mathrm{kW} / \mathrm{K}\right.$ or $\left.\mathrm{kW} /{ }^{\circ} \mathrm{C}\right]$ \\
\hline EMAT & Heat exchanger minimal approach temperature $[\mathrm{K}]$ \\
\hline$h$ & General heat transfer coefficient $\left[\mathrm{kW} /\left(\mathrm{m}^{2} \mathrm{~K}\right)\right]$ \\
\hline hcu & Cold utility heat transfer coefficient $\left[\mathrm{kW} /\left(\mathrm{m}^{2} \mathrm{~K}\right)\right]$ \\
\hline$h h$ & Hot stream heat transfer coefficient $\left[\mathrm{kW} /\left(\mathrm{m}^{2} \mathrm{~K}\right)\right]$ \\
\hline IsLinked & $\begin{array}{l}\text { Binary vector for stream identification as a continuation of the previous one } \\
{[-]}\end{array}$ \\
\hline$M$ & Master matrix [-] \\
\hline Par & Vector containing information on parallel unit numbers per stream [-] \\
\hline psupply & Stream supply pressure [K] \\
\hline ptarget & Stream target pressure $[\mathrm{K}]$ \\
\hline
\end{tabular}




\begin{tabular}{|c|c|}
\hline Rel & Electricity revenue price $[\$ / \mathrm{kW}]$ \\
\hline Tcuin & Cold utility inlet temperature $[\mathrm{K}]$ \\
\hline Tсиоut & Cold utility outlet temperature [K] \\
\hline Thuin & Hot utility inlet temperature [K] \\
\hline Thuout & Hot utility outlet temperature $[\mathrm{K}]$ \\
\hline Tsupply & Stream supply temperature $[\mathrm{K}]$ \\
\hline Ttarget & Stream target temperature $[\mathrm{K}]$ \\
\hline$T L B$ & Temperature lower bound [K] \\
\hline TUB & Temperature upper bound [K] \\
\hline Ucu & Cooler global heat transfer coefficient $\left[\mathrm{kW} /\left(\mathrm{m}^{2} \mathrm{~K}\right)\right]$ \\
\hline$\eta_{c}$ & Isentropic efficiency for compressors [-] \\
\hline$\eta_{t}$ & Isentropic efficiency for turbines [-] \\
\hline$\kappa$ & Polytropic exponent [-] \\
\hline$\mu$ & Joule-Thompson coefficient [K/MPa] \\
\hline \multicolumn{2}{|l|}{ Functions } \\
\hline AreaCost & Calculates the heat transfer device cost as a function of its area [\$] \\
\hline SpecificEnthalpy & Calculates specific enthalpy for a given temperature [kJ/kg] \\
\hline \multicolumn{2}{|l|}{ Indexes: } \\
\hline$f$ & Stream fraction at pressure manipulation stage [-] \\
\hline$i$ & Hot stream $[-]$ \\
\hline$j$ & Cold stream [-] \\
\hline$k$ & Stage [-] \\
\hline$m$ & Hot utility [-] \\
\hline$n$ & Cold utility [-] \\
\hline$o i$ & Original hot stream [-] \\
\hline$o j$ & Original cold stream [-] \\
\hline$s$ & Shaft $[-]$ \\
\hline$w$ & General stream [-] \\
\hline \multicolumn{2}{|l|}{ Sets: } \\
\hline$N C$ & Cold streams [-] \\
\hline$N C U$ & Cold utilities [-] \\
\hline$N F$ & Stream split fractions in WEN blocks [-] \\
\hline$N G$ & General streams [-] \\
\hline$N H$ & Hot streams [-] \\
\hline NHU & Hot utilities [-] \\
\hline NOC & Original cold streams [-] \\
\hline NS & Stages $[-]$ \\
\hline$N S h$ & Shafts $[-]$ \\
\hline$N T$ & Stream types [-] \\
\hline \multicolumn{2}{|l|}{ Acronyms } \\
\hline CC & Capital costs \\
\hline
\end{tabular}




$\begin{array}{ll}\text { HEN } & \text { Heat exchanger network } \\ \text { HP } & \text { High-pressure } \\ \text { ITM } & \text { Ion transport membrane } \\ \text { LP } & \text { Low-pressure } \\ \text { MINLP } & \text { Mixed-integer nonlinear programming } \\ \text { OC } & \text { Operating costs } \\ \text { RFO } & \text { Rocket fireworks optimization } \\ \text { SA } & \text { Simulated annealing } \\ \text { SSTC } & \text { Single-shaft-turbine-compressor } \\ \text { SWS } & \text { Stagewise superstructure } \\ \text { TAC } & \text { Total annual costs } \\ \text { WEN } & \text { Work exchange network } \\ \text { WHEN } & \text { Work and heat exchange network }\end{array}$

\section{References}

[1] Taborek J. Shell-and-tube heat exchangers. In: Schlünder EU, Bell KJ, Chisholm D, Hewitt G, Schmidt FW, Spalding DB, et al., editors. Heat Exch. Des. Handb. 1st ed., Düsseldorf: Hemisphere Publishing; 1983.

[2] Linnhoff B, Hindmarsh E. The pinch design method for heat exchanger networks. Chem Eng Sci 1983;38:745-63. doi:10.1016/0009-2509(83)80185-7.

[3] Yee TF, Grossmann IE. Simultaneous optimization models for heat integration-II. Heat exchanger network synthesis. Comput Chem Eng 1990;14:1165-84. doi:10.1016/00981354(90)85010-8.

[4] Klemeš JJ, Kravanja Z. Forty years of Heat Integration: Pinch Analysis (PA) and Mathematical Programming (MP). Curr Opin Chem Eng 2013;2:461-74. doi:10.1016/J.COCHE.2013.10.003.

[5] Klemeš JJ, Varbanov PS, Walmsley TG, Jia X. New directions in the implementation of Pinch Methodology (PM). Renew Sustain Energy Rev 2018;98:439-68. doi:10.1016/J.RSER.2018.09.030.

[6] Liu G, Zhou H, Shen R, Feng X. A graphical method for integrating work exchange network. Appl Energy 2014;114:588-99. doi:10.1016/J.APENERGY.2013.10.023.

[7] Cheng C-Y, Cheng S-W, Fan L-T. Flow work exchanger. AIChE J 1967;13:438-42. doi:10.1002/aic.690130310.

[8] Andrews WT, Laker DS. A twelve-year history of large scale application of workexchanger energy recovery technology. Desalination 2001;138:201-6. doi:10.1016/S0011-9164(01)00265-X.

[9] Huang YL, Fan LT. Analysis of a Work Exchanger Network. Ind Eng Chem Res 1996;35:3538. doi:10.1021/IE9507383. 
[10] Zhuang Y, Liu L, Zhang L, Du J. Upgraded Graphical Method for the Synthesis of Direct Work Exchanger Networks. Ind Eng Chem Res 2017;56:14304-15. doi:10.1021/acs.iecr.7b03319.

[11] Amini-Rankouhi A, Huang Y. Prediction of maximum recoverable mechanical energy via work integration: A thermodynamic modeling and analysis approach. AIChE J 2017;63:4814-26. doi:10.1002/aic.15813.

[12] Aspelund A, Berstad DO, Gundersen T. An Extended Pinch Analysis and Design procedure utilizing pressure based exergy for subambient cooling. Appl Therm Eng 2007;27:2633-49. doi:10.1016/J.APPLTHERMALENG.2007.04.017.

[13] Wechsung A, Aspelund A, Gundersen T, Barton PI. Synthesis of heat exchanger networks at subambient conditions with compression and expansion of process streams. AIChE J 2011;57:2090-108. doi:10.1002/aic.12412.

[14] Fu C, Gundersen T. Correct integration of compressors and expanders in above ambient heat exchanger networks. Energy 2016;116:1282-93. doi:10.1016/J.ENERGY.2016.05.092.

[15] Onishi VC, Quirante N, Ravagnani MASS, Caballero JA. Optimal synthesis of work and heat exchangers networks considering unclassified process streams at sub and aboveambient conditions. Appl Energy 2018;224:567-81. doi:10.1016/J.APENERGY.2018.05.006.

[16] Blurton RN, Ruckley LJ. CONSERVATION OF ENERGY ON A 40,000 BPSD FLUID CATALYTIC CRACKING UNIT UTILISING A FLUE GAS EXPANSION TURBINE. Energy Money, Mater. Eng., Elsevier; 1982, p. T2-49-T2-62. doi:10.1016/B978-0-08028774-4.50018-X.

[17] Sadeghbeigi R. Fluid Catalytic Cracking Handbook. Elsevier Inc.; 2012. doi:10.1016/C2010-0-67291-9.

[18] Poe WA, Mokhatab S. Introduction to Natural Gas Processing Plants. Model. Control. Optim. Nat. Gas Process. Plants, Elsevier; 2017, p. 1-72. doi:10.1016/b978-0-12-8029619.00001-2.

[19] Bucklin R. Method and Equipment for Treating Hydrocarbon Gases for Pressure Reduction and Condensate Recovery. U.S. Patent No. 3292380, 1966.

[20] Kosarim VN, Pryamitsyn EI, Smirnov EN. Turboexpander-compressors for air separation facilities. Chem Pet Eng 1994;30:220-3. doi:10.1007/BF01150942.

[21] Yang S, Chen S, Chen X, Zhang X, Hou Y. Study on the coupling performance of a turboexpander compressor applied in cryogenic reverse Brayton air refrigerator. Energy Convers Manag 2016;122:386-99. doi:10.1016/j.enconman.2016.05.092.

[22] Krishnasing R, Mariotti G, Byrne K. Turboexpander-Compressor Technology for Ethylene Plants. AIChE Spring Natl. Meet., San Antonio, TX: 2010. 
[23] Razib MS, Hasan MMF, Karimi IA. Preliminary synthesis of work exchange networks. Comput Chem Eng 2012;37:262-77. doi:10.1016/j.compchemeng.2011.09.007.

[24] Du J, Zhuang Y, Liu L lin, Li J long, Fan J, Meng Q wei. Synthesis of indirect work exchanger network based on transshipment model. Comput. Aided Chem. Eng., vol. 37, Elsevier B.V.; 2015, p. 1139-44. doi:10.1016/B978-0-444-63577-8.50035-8.

[25] Onishi VC, Ravagnani MASS, Caballero JA. Simultaneous synthesis of heat exchanger networks with pressure recovery: Optimal integration between heat and work. AIChE J 2014;60:893-908. doi:10.1002/aic.14314.

[26] Onishi VC, Ravagnani MASS, Caballero JA. Simultaneous synthesis of work exchange networks with heat integration. Chem Eng Sci 2014;112:87-107. doi:10.1016/j.ces.2014.03.018.

[27] Onishi VC, Ravagnani MASS, Caballero JA. Retrofit of heat exchanger networks with pressure recovery of process streams at sub-ambient conditions. Energy Convers Manag 2015;94:377-93. doi:10.1016/j.enconman.2015.02.002.

[28] Huang K, Karimi IA. Work-heat exchanger network synthesis (WHENS). Energy 2016;113:1006-17. doi:10.1016/j.energy.2016.07.124.

[29] Onishi VC, Ravagnani MASS, Jiménez L, Caballero JA. Multi-objective synthesis of work and heat exchange networks: Optimal balance between economic and environmental performance. Energy Convers Manag 2017;140:192-202. doi:10.1016/j.enconman.2017.02.074.

[30] Nair SK, Nagesh Rao H, Karimi IA. Framework for work-heat exchange network synthesis (WHENS). AIChE J 2018. doi:10.1002/aic.16129.

[31] Pavão L V., Costa CBB, Ravagnani MASS. A new framework for work and heat exchange network synthesis and optimization. Energy Convers Manag 2019;183:617-32. doi:10.1016/J.ENCONMAN.2019.01.018.

[32] Pavão L V, Costa CBB, Ravagnani MASS. An enhanced stage-wise superstructure for heat exchanger networks synthesis with new options for heaters and coolers placement. Ind Eng Chem Res 2018;57:2560-73.

[33] Pavão L V., Costa CBB, Ravagnani MASS. Work and heat exchange network synthesis considering multiple electricity-related scenarios. Energy 2019;182:932-53. doi:10.1016/J.ENERGY.2019.06.079.

[34] Fu C, Vikse M, Gundersen T. Work and heat integration: An emerging research area. Energy 2018;158:796-806. doi:10.1016/J.ENERGY.2018.06.030.

[35] Yu H, Fu C, Vikse M, Gundersen T. Work and heat integration-A new field in process synthesis and process systems engineering. AIChE J 2018:aic.16477. doi:10.1002/aic.16477.

[36] Seider WD, Lewin DR, Seader JD, Widagdo S, Gani R, Ng KM. Product and Process 
Design Principles: Synthesis, Analysis and Evaluation. 4th ed. New York: Wiley; 2017.

[37] Aspen Technology. Aspen Plus Ammonia Model 2008.

[38] Pavão LV, Costa CBB, Ravagnani MASS, Jiménez L. Large-scale heat exchanger networks synthesis using simulated annealing and the novel rocket fireworks optimization. AIChE J 2017;63:1582-601. doi:10.1002/aic.15524.

[39] Pavão L V., Costa CBB, Ravagnani MASS. Work and heat exchange network synthesis considering multiple electricity-related scenarios. Energy 2019;182:932-53. doi:10.1016/j.energy.2019.06.079.

[40] Turton R, Bailie RC, Whiting WB, Shaeiwitz JA, Bhattacharyya D. Analysis, Synthesis, and Design of Chemical Processes. 4th ed. Ann Arbor, MI, USA: Prentice Hall; 2012.

[41] Fu C, Gundersen T. Heat and work integration: Fundamental insights and applications to carbon dioxide capture processes. Energy Convers Manag 2016;121:36-48. doi:10.1016/J.ENCONMAN.2016.04.108.

[42] DOE/NETL. Pulverized coal oxycombustion power plants. In: Bituminous coal to electricity. vol. 1. 2008.

[43] U.S. Energy Information Administration (EIA). US Dep Energy 2019. https://www.eia.gov/ (accessed March 10, 2019).

[44] UNIDO, IFDC. Fertilizer manual. 3rd ed. Dordrecht, Netherlands: Kluwer Academic Publishers; 1998. 